\title{
PAM haploinsufficiency does not accelerate the development of diet- and human IAPP-induced diabetes in mice
}

\author{
Yi-Chun Chen ${ }^{1} \cdot$ Richard E. Mains ${ }^{2} \cdot$ Betty A. Eipper $^{2} \cdot$ Brad G. Hoffman $^{1} \cdot$ Traci A. Czyzyk $^{3} \cdot$ John E. Pintar ${ }^{4}$. \\ C. Bruce Verchere ${ }^{1,5,6}$
}

Received: 4 May 2019 / Accepted: 28 October 2019 / Published online: 27 January 2020

(C) Springer-Verlag GmbH Germany, part of Springer Nature 2020

\begin{abstract}
Aims/hypothesis Peptide hormones are first synthesised as larger, inactive precursors that are converted to their active forms by endopeptidase cleavage and post-translational modifications, such as amidation. Recent, large-scale genome-wide studies have suggested that two coding variants of the amidating enzyme, peptidylglycine $\alpha$-amidating monooxygenase (PAM), are associated with impaired insulin secretion and increased type 2 diabetes risk. We aimed to elucidate the role of PAM in modulating beta cell peptide amidation, beta cell function and the development of diabetes.

Methods PAM transcript and protein levels were analysed in mouse islets following induction of endoplasmic reticulum (ER) or cytokine stress, and PAM expression patterns were examined in human islets. To study whether haploinsufficiency of PAM accelerates the development of diabetes, $\mathrm{Pam}^{+/-}$and $\mathrm{Pam}^{+/+}$mice were fed a low-fat diet (LFD) or high-fat diet (HFD) and glucose homeostasis was assessed. Since aggregates of the PAM substrate human islet amyloid polypeptide (hIAPP) lead to islet inflammation and beta cell failure, we also investigated whether PAM haploinsufficiency accelerated hIAPP-induced diabetes and islet amyloid formation in $\mathrm{Pam}^{+/-}$and $\mathrm{Pam}^{+/+}$mice with beta cell expression of hIAPP.

Results Immunostaining revealed high expression of PAM in alpha, beta and delta cells in human pancreatic islets. Pam mRNA and PAM protein expression were reduced in mouse islets following administration of an HFD, and in isolated islets following induction of ER stress with thapsigargin, or cytokine stress with IL-1 $\beta$, IFN- $\gamma$ and TFN- $\alpha$. Despite Pam ${ }^{+/-}$only having $50 \%$ PAM expression and enzyme activity as compared with $\mathrm{Pam}^{+/+}$mice, glucose tolerance and body mass composition were comparable in the two models. After 24 weeks of HFD, both $\mathrm{Pam}^{+/-}$and $\mathrm{Pam}^{+/+}$mice had insulin resistance and impaired glucose tolerance, but no differences in glucose tolerance, insulin sensitivity or plasma insulin levels were observed in PAM haploinsufficient mice. Islet amyloid formation and beta cell function were also similar in $\mathrm{Pam}^{+/-}$and $\mathrm{Pam}^{+/+}$mice with beta cell expression of hIAPP.

Conclusions/interpretation Haploinsufficiency of PAM in mice does not accelerate the development of diet-induced obesity or hIAPP transgene-induced diabetes.
\end{abstract}

Electronic supplementary material The online version of this article (https://doi.org/10.1007/s00125-019-05060-z) contains peer-reviewed but unedited supplementary material, which is available to authorised users.

\section{Bruce Verchere}

bverchere@bcchr.ca

1 Department of Surgery, University of British Columbia and BC Children's Hospital Research Institute, 950 West 28th Avenue, Vancouver, BC V5Z 4H4, Canada

2 Department of Neuroscience, University of Connecticut Health Center, Farmington, CT, USA

3 Division of Cardio-renal and Metabolic Disease, Merck Research Laboratories, San Francisco, CA, USA
4 Department of Neuroscience and Cell Biology, Rutgers Robert Wood Johnson Medical School, Piscataway, NJ, USA

5 Department of Pathology and Laboratory Medicine, University of British Columbia and BC Children's Hospital Research Institute, Vancouver, BC, Canada

6 Centre for Molecular Medicine and Therapeutics, University of British Columbia, Vancouver, BC, Canada 


\section{Research in context}

\section{What is already known about this subject?}

- Peptidylglycine a-amidating monooxygenase (PAM) is the only enzyme that amidates neuroendocrine peptides (such as islet amyloid polypeptide [IAPP])

- $\quad$ Aged $\mathrm{Pam}^{+/-}$mice display mild glucose intolerance

- Whole genome sequencing studies have shown that two coding variants of PAM are associated with impaired insulin secretion and increased type 2 diabetes risk

\section{What is the key question?}

- Does PAM modulate IAPP amidation and beta cell function, and the development of diet-induced obesity and human IAPP (hIAPP)-transgene-induced diabetes?

\section{What are the new findings?}

- Expression of PAM mRNA and protein are reduced in islets exposed to endoplasmic reticulum (ER) and cytokine stress

- Glucose-stimulated insulin secretion is not affected by PAM haploinsufficiency in mice

- PAM haploinsufficiency does not accelerate the development of diet- or hIAPP-induced diabetes in mice, suggesting that the increased type 2 diabetes susceptibility associated with PAM variants is not likely to be explained by decreased PAM expression

How might this impact on clinical practice in the foreseeable future?

- This study provides insight into the role of PAM in the pathogenesis of type 2 diabetes, and information of potential value for treatment of type 2 diabetes, especially in PAM-variant carriers

Keywords Amidation · Glucose homeostasis · IAPP · Insulin secretion · PAM

$\begin{array}{ll}\text { Abbreviations } & \\ \text { CCK } & \text { Cholecystokinin } \\ \text { ER } & \text { Endoplasmic reticulum } \\ \text { HFD } & \text { High-fat diet } \\ \text { hIAPP } & \text { Human islet amyloid polypeptide } \\ \text { hIAPP Tg/0 } & \text { hIAPP transgenic mice } \\ \text { IAPP } & \text { Islet amyloid polypeptide } \\ \text { LFD } & \text { Low-fat diet } \\ \text { NPY } & \text { Neuropeptide Y } \\ \text { PAL } & \text { Peptidyl- } \alpha \text {-hydroxyglycine } \alpha \text {-amidating lyase } \\ \text { PAM } & \text { Peptidylglycine } \alpha \text {-amidating monooxygenase } \\ \text { PHM } & \text { Peptidylglycine } \alpha \text {-hydroxylating } \\ & \text { monooxygenase } \\ \text { RNA-Seq } & \text { RNA sequencing } \\ \text { TRH } & \text { Thyrotropin releasing hormone }\end{array}$

\section{Introduction}

Neuroendocrine hormones are biological messengers secreted by neurons or endocrine glands, acting on target tissues and coordinating whole-body homeostasis, including metabolism. Peptide hormones are a class of neuroendocrine hormones that are made as larger and inactive precursors; they are processed to smaller and functionally active hormones via sequential peptide cleavage mediated by endopeptidases. Many peptide hormones also undergo post-translational modifications, including C-terminal amidation, which occurs in more than $50 \%$ of neuroendocrine peptides and is mediated exclusively by the enzyme peptidylglycine $\alpha$-amidating monooxygenase (PAM) [1].

The essential role of PAM has been demonstrated in multiple model organisms. For example, the absence of Pam in mice and zebrafish leads to embryonic lethality [2-4]. Pam whole-body heterozygous knockout mice have a myriad of behavioural defects and develop increased adiposity and mild glucose intolerance with age $[2,5]$. Two $P A M$ coding variants (rs35658696 and rs78408340) were recently reported to be associated with reduced insulinogenic index and elevated risk of type 2 diabetes in humans [6-10]. Notably, pancreatic islets from $P A M$ variant rs35658696 donors were found to have mildly impaired glucose-stimulated insulin secretion, possibly due to defective granule trafficking and exocytosis [9]. The authors implicated decreased amidation and function of chromogranin $\mathrm{A}$ as a possible mechanism underlying the impaired beta cell function seen in carriers of $P A M$ variants. 
Together, the available data suggest that PAM activity is important for normal beta cell function.

PAM has two enzymatically active subunits, peptidylglycine $\alpha$-hydroxylating monooxygenase (PHM) and peptidyl- $\alpha$-hydroxyglycine $\alpha$-amidating lyase (PAL). Peptides that have a $\mathrm{COOH}$-terminal glycine residue are first converted into hydroxyl-glycine intermediates by PHM; these intermediates are then cleaved by PAL, yielding $\mathrm{COOH}-$ terminally amidated peptides [1]. Although the catalytic cores of PHM and PAL have been structurally characterised [11, 12], how the PAM variants rs35658696 and rs 78408340 (both of which reside in the PAL domain) alter enzyme structure and reduce PAM activity or stability is not fully understood. PAM activity is also regulated by a number of hormonal and environmental stimuli. For example, mice fed a copper-deficient diet have increased serum PAM activity [5] and neuroendocrine cells cultured under hypoxic conditions have lowered abundance of amidated peptides [13]. Whether pathological stresses present in diabetes may affect PAM expression or activity remains unclear.

In pancreatic islets, there are a number of amidated peptides that are thought to play roles in coordinating intracellular communication, maintaining beta cell function, and supporting cell survival, including chromogranin A, glucagon-like peptide-1 (GLP-1), cholecystokinin (CCK), neuropeptide Y (NPY) and islet amyloid polypeptide (IAPP). Among these PAM product peptides, IAPP is the second most abundant peptide made in islets. Human, but not rodent, IAPP aggregates to form islet amyloid deposits in type 2 diabetes, likely contributing to islet inflammation and beta cell failure [14-16]. It is plausible that PAMmediated IAPP amidation could alter IAPP aggregation kinetics and, by extension, that PAM deficiency could influence IAPP-related islet pathology [17].

We aimed to determine whether and how PAM haploinsufficiency might contribute to insulin secretory defects and the development of diabetes. We examined PAM expression in human islet cells, and evaluated PAM expression in rodent islets following exposure to endoplasmic reticulum (ER) or cytokine stress. We studied the impact of PAM deficiency on glucose homeostasis and diabetes development using two mouse models: mice challenged with a high-fat diet (HFD) or mice with beta cell expression of amyloidogenic human IAPP (hIAPP). These studies may provide insight into the role of PAM and islet peptide amidation in beta cell function and glucose homeostasis.

\section{Methods}

Human pancreas and islet tissue Paraformaldehyde-fixed, paraffin-embedded pancreatic tissue sections were received from the Network for Pancreatic Organ Donors with
Diabetes (nPOD) via coordination through the University of Florida (Gainesville, FL, USA) [18]. Human islets were acquired from the Clinical Islet Laboratory at the University of Alberta [19]. Upon arrival, islets were hand-picked, washed in Dulbecco's phosphate-buffered saline and stored at $-20^{\circ} \mathrm{C}$. The use of human pancreatic tissue was approved by the $\mathrm{BC}$ Children's Hospital Institutional Review Board. Details of the organ donor characteristics are presented in electronic supplementary material (ESM) Table 1; the checklist for reporting human islet preparations used in research is also presented in the ESM.

Animal studies $\mathrm{C} 57 \mathrm{BL} / 6 \mathrm{~J}$ and hIAPP transgenic mice (hIAPP Tg/0; FVB/N-Tg(Ins2-IAPP)RHFSoel/J) were purchased from The Jackson Laboratory (Bar Harbor, ME, USA). $\mathrm{Pam}^{+-}$mice (back-crossed more than ten generations onto the $\mathrm{C} 57 \mathrm{BL} / 6 \mathrm{~J}$ background) were obtained from the University of Connecticut Health Center (Farmington, CT, USA), and maintained on a 14/10 h light/dark cycle, with a chow diet (6\% fat; Teklad 2918, Huntingdon, UK) and water ad libitum, in the animal facility of BC Children's Hospital Research Institute (Vancouver, BC, Canada) [2]. hIAPP Tg/0 $\mathrm{Pam}^{+/-}$mice and littermate control mice (hIAPP Tg/0 $\mathrm{Pam}^{+/+}$, hIAPP 0/0 $\mathrm{Pam}^{+/+}$and hIAPP 0/0 $\mathrm{Pam}^{+/-}$) were generated by crossing $\mathrm{Pam}^{+-}$males with hIAPP Tg/0 females (all experimental mice were on a mixed first filial generation (F1) $\mathrm{FVB} / \mathrm{N} \times \mathrm{C} 57 \mathrm{BL} / 6 \mathrm{~J}$ background). For metabolic studies, mice were assigned to receive either a low-fat diet (LFD; $10 \%$ fat; D $12450 \mathrm{H}$; Research Diets, New Brunswick, NJ, USA) or an HFD (45\% fat; D12451; Research Diets), through a simple randomisation method, starting at 8 weeks of age. Metabolic assays were performed in a blinded fashion and are described in the ESM Methods; briefly these included body weight, blood glucose (by glucometer), intraperitoneal glucose tolerance test (IPGTT), intraperitoneal insulin tolerance test (IPITT), plasma insulin (by ELISA), and lean and fat mass (using a body composition analyser). All protocols were approved by the Animal Care and Use Committee at the University of British Columbia.

Islet studies Islets from mice and Lewis rats (purchased from Charles Rivers Laboratory, Sherbrooke, QC, Canada) were isolated and cultured as described [20], and insulin secretion was assessed via ELISA, as described in the ESM Methods. Prior to measurement of PAM protein and mRNA levels, mouse or rat islets were treated for $72 \mathrm{~h}$ with $25 \mathrm{mmol} / 1$ glucose, or $16 \mathrm{~h}$ with $1 \mu \mathrm{mol} / 1$ thapsigargin (stock solution dissolved in DMSO; Sigma-Aldrich, St Louis, MO, USA), or $16 \mathrm{~h}$ with a proinflammatory cytokine cocktail $(50 \mathrm{U} / \mathrm{ml} \mathrm{IL}-$ $1 \beta, 1000 \mathrm{U} / \mathrm{ml} \mathrm{IFN}-\gamma$ and $1000 \mathrm{U} / \mathrm{ml}$ TNF- $\alpha$; R\&D systems, Oakville, ON, Canada). PAM, amidated IAPP and non- 
amidated IAPP protein expression levels were analysed by immunoblotting using anti PAM (JH1761; Eipper and Mains laboratories, Farmington, CT, USA) [21], anti-amidated IAPP (F025; MedImmune, San Diego, CA, USA), and anti-nonamidated IAPP (F084; MedImmune) antibodies, respectively (see ESM Table 2 for antibody information). Pam, Ins2, Iapp, $S c g 5$, Ddit3, Nos2, rplP and B2m transcript levels were analysed using SYBR Green-based (Fast SYBR; Invitrogen, Burlington, ON, Canada) quantitative real-time PCR (ViiA7 Real-Time PCR System; Applied Biosystems, Waltham, MA, USA). Primer sequences are listed in ESM Table 3.

Immunostaining PAM expression in human islet cells was analysed by immunofluorescence staining using primary antibodies against PAM (JH1761), insulin, glucagon and somatostatin, and secondary Alexa Fluor-conjugated antibodies (ESM Table 2). Islet amyloid was analysed by thioflavin S staining (Sigma), as described previously [22]. Images were acquired using a Leica TCS SP5 confocal microscope (Leica Microsystems, Concord, ON, Canada). Amyloid severity was quantified in a blinded fashion by CellProfiler (Cambridge, MA, USA) and presented as per cent thioflavin $\mathrm{S}^{+}$area/insulin ${ }^{+}$area.

PHM and PAL activity assays Islet PHM and PAL enzyme activity were assayed as described [23]. In brief, 100 handpicked islets were washed in Dulbecco's phosphate-buffered saline (Thermo Scientific, Waltham, MA, USA), frozen, and lysed in $20 \mathrm{mmol} / \mathrm{l} \mathrm{N}$-[Tris(hydroxymethyl)methyl]-2aminoethanesulfonic acid sodium salt (sodium TES; pH 7.4), $10 \mathrm{mmol} / \mathrm{l}$ mannitol, $1 \mathrm{mg} / \mathrm{ml}$ BSA, $1 \%$ (vol./vol.) Triton X-100 (Surfact-Amps X-100; Thermo Scientific) buffer. PHM activity was measured using in-house generatedand ${ }^{125}$ I-labelled acetyl-Tyr-Val-Gly as a substrate and PAL was measured using in-house generated- and ${ }^{125}$ I-labelled acetyl-Tyr-Val- $\alpha$-hydroxyglycine as substrate. Specific activity is expressed as picomoles of the product formed per $h$ ( $\mathrm{pmol} / \mathrm{h}$ ) per $\mu \mathrm{g}$ protein in islet lysates.

Identification of PAM transcript isoforms in human and mouse beta cells Reads from human and mouse beta cell RNA sequencing (RNA-Seq) libraries (GSE116559 [www. ncbi.nlm.nih.gov/geo/query/acc.cgi?acc=GSE116559] and GSE73289 [www.ncbi.nlm.nih.gov/geo/query/acc.cgi?acc= GSE73289]) [24] were assembled into transcripts using StringTie (https://ccb.jhu.edu/software/stringtie/; accessed 4 July 2019), with reference transcriptomes (GRCh38.89 [ftp://ftp.ensembl.org/pub/current_gtf/homo_sapiens/; accessed 4 July 2019] and University of California Santa Cruz [UCSC] Genome Browser known genes [https://genome. ucsc.edu/cgi-bin/hgGateway, accessed 17 May 2016]) used to guide the assembly and allow for the identification of known and unknown PAM isoforms [25, 26]. Diagrams of human and mouse PAM isoforms were generated using
Gene Structure Display Server 2.0 (GSDS; http://gsds.cbi. pku.edu.cn/) [27], with domains highlighted based on UniProt (www.uniprot.org/; accessed 15 July 2019) protein domain annotation and a reference publication [28].

Statistical analysis Datasets were first analysed for normal distribution. For datasets that passed the normality test, differences between groups were examined for significance $(p$ value $<0.05$ ) using either a two-tailed Student's $t$ test, or one-way ANOVA followed by Tukey's post test. For datasets that failed the normality test, non-parametric tests (MannWhitney or Kruskal-Wallis) followed by Dunn's post test were performed. Diabetes incidence was displayed as survival curves and analysed by logrank test. All statistical analysis was performed using Prism 8 (GraphPad Software, San Diego, CA, USA).

\section{Results}

PAM is expressed in human and mouse islet cells Coding variants of $P A M$ are associated with reduced insulinogenic index, suggesting that PAM defects might have an impact on islet function. We first analysed PAM expression patterns in human and mouse islets by double-immunofluorescence staining for PAM and islet hormones. We found immunoreactivity for PAM in insulin $^{+}$, glucagon ${ }^{+}$and somatostatin ${ }^{+}$cells in pancreases from non-diabetic donors (Fig. 1a), in keeping with immunostaining findings of others [9] and publicly available transcriptome data indicating expression of PAM in human islet cells [29]. The pattern of PAM expression in mouse islets was similar (Fig. 1b), with robust PAM immunoreactivity observed in all murine insulin $^{+}$, glucagon ${ }^{+}$and somatostatin ${ }^{+}$cells. To compare and identify novel PAM transcript isoforms expressed in human and mouse beta cells, we used RNA-Seq data from an online database [24] and an in-house database. Sequence alignment and protein domain prediction showed that one of the major PAM isoforms, isoform A (which encodes the PAM3 protein), does not contain the transmembrane domain. We also identified the novel PAM isoform $\mathrm{B}$, which lacks part of the PHM domain (Fig. 1c). The Pam transcript sequence is well-conserved in rodent beta cells, with all three isoforms encoding the full-length PAM protein with small sequence variations. Isoform A encodes a 979 amino-acid-long PAM1 protein, isoform B is an in-frame deletion of PAM1 and encodes a 978 aminoacid-long protein, and isoform $\mathrm{C}$ encodes PAM2 protein (lacking exon 14 in the linker region) (Fig. 1d). To evaluate PAM protein expression, we analysed isolated islets from mouse, rat and a non-diabetic human donor 
a

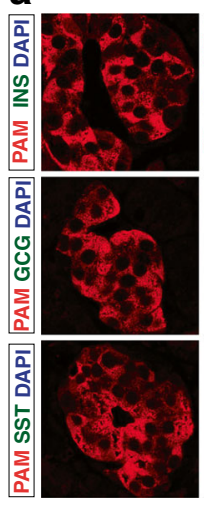

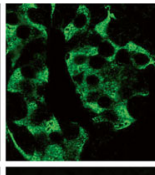
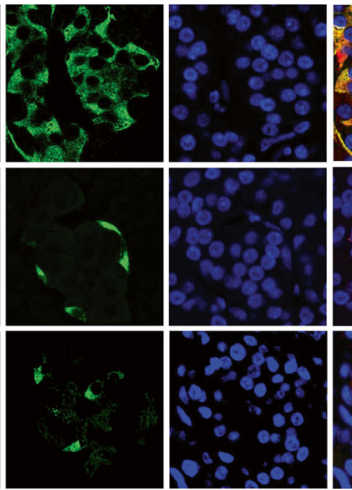

b

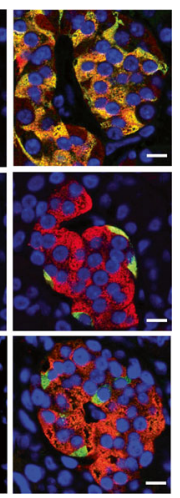

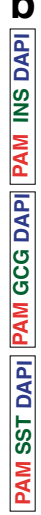
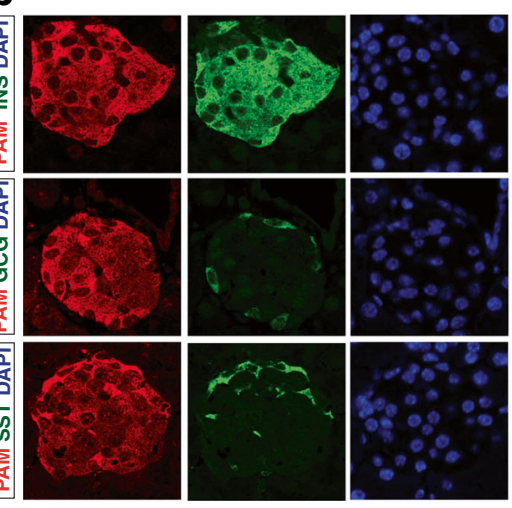

C

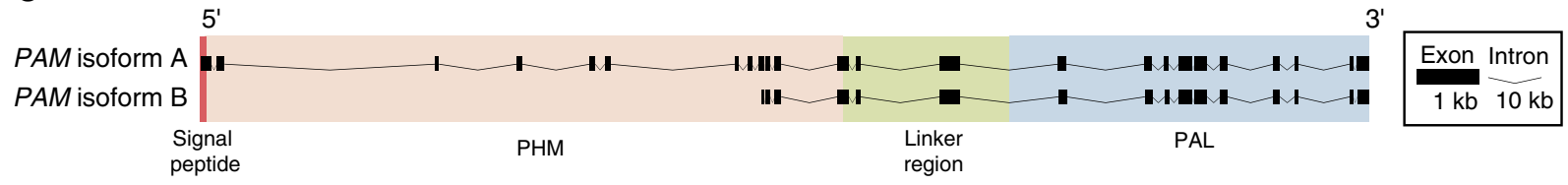

d

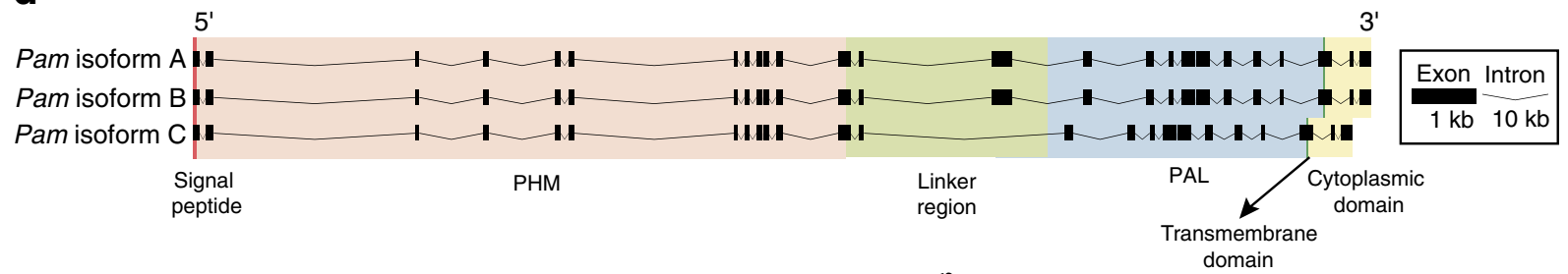

\section{e}

PAM antibody (JH1761) binding site

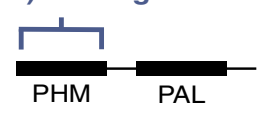

Fig. 1 PAM expression in human and rodent islets. Representative images of pancreatic sections from (a) a non-diabetic donor (nPOD no. 6030) and (b) a 16-week-old male C57BL/6J mouse, which were stained for PAM, insulin (INS), glucagon (GCG), somatostatin (SST) and DAPI. Scale bars, $10 \mu \mathrm{m}$. (c, d) Sequence alignments of major PAM transcript

by immunoblotting, using an antibody raised against rat PHM domain (JH1761). Because the JH1761 antibody has higher affinity toward rat PAM, we adjusted the amount of islet lysate loaded to reveal PAM expression patterns in mouse, rat and human islets. We found that islet PAM protein expression patterns are comparable among all three species (Fig. 1e).

Cell stresses present in diabetes could have an impact on PAM expression and activity. We found that 3 day culture of mouse islets in high $(25 \mathrm{mmol} / \mathrm{l})$ glucose induced a 2.4-fold increase in Pam mRNA levels (Fig. 2a). By contrast, islets from mice fed an HFD for 14 weeks had reduced Pam transcript levels (Fig. 2b). Treatment of islets ex vivo with the ER stress inducer thapsigargin led to a significant increase in the expression of the ER stress gene Ddit3, whereas proinflammatory cytokines led to increased expression of the cytokineresponsive element Nos2 (Fig. 2d, e). Thapsigargin and cytokines both caused moderate reductions in Pam transcript (Fig. 

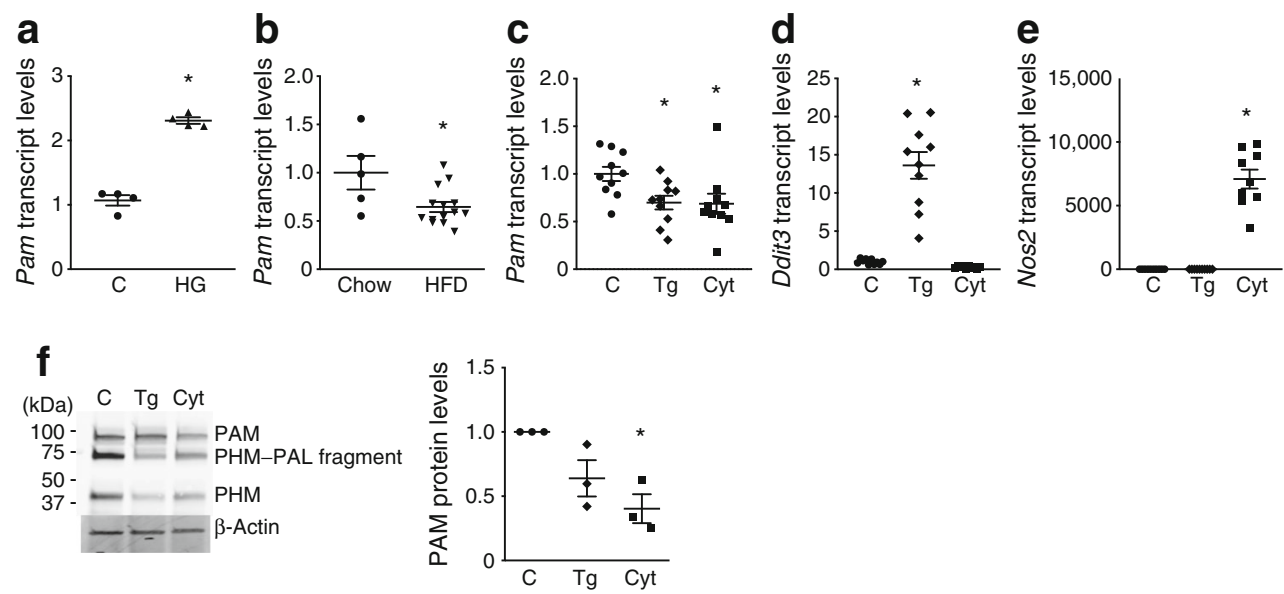

Fig. 2 PAM expression levels in stress-treated rodent islets. (a, b) Pam transcript levels in mouse islets from 12-16-week-old male C57BL/6J mice incubated in media containing $11 \mathrm{mmol} / 1$ glucose (control [C]) or $25 \mathrm{mmol} / 1$ glucose (high glucose [HG]) for 3 days $(n=4)(\mathbf{a})$ and islets from 8-week-old male C57BL/6J mice fed for 14 weeks on a $6 \%$ fat control (chow) or $45 \%$ fat HFD ( $n=5$ and $n=14$, respectively) (b) were analysed by quantitative real-time PCR. (c-e) Pam, Ddit 3 and Nos 2 transcript levels in islets from 12-16-week-old male C57BL/6J mice, treated for $16 \mathrm{~h}$ with DMSO (control [C]), $1 \mu \mathrm{mol} / 1$ thapsigargin $(\mathrm{Tg})$, or a cytokine cocktail containing $50 \mathrm{U} / \mathrm{ml} \mathrm{IL}-1 \beta, 1000 \mathrm{U} / \mathrm{ml} \mathrm{IFN-} \gamma$ and $1000 \mathrm{U} / \mathrm{ml} \mathrm{TNF}-\alpha$ (Cyt) $(n=10)$, were analysed by quantitative real-time PCR using $B 2 m$ as reference gene and expressed as fold over control. (f) PAM protein expression in isolated islets from 24-week-old male Lewis rats, treated as mouse islets in $(\mathbf{c}-\mathbf{e})$, was analysed by immunoblotting using an affinity-purified antibody specific for PAM (JH1761) $(n=3)$. PAM protein level was quantified using $\beta$-actin as a reference protein and expressed as fold over control. Data are shown as mean \pm SEM. $* p<0.05$ vs control 2c) and cytokine treatment reduced levels of PAM protein (Fig. 2f). Of note, the expression of islet peptide hormones were also significantly reduced upon ER stress (Ins2) or cytokine treatment (Ins2, Iapp and Scg5) and significantly upregulated by glucose treatment ( $S c g 5$ ), suggesting that PAM expression may be a reflection of beta cell activity and health (ESM Fig. 1).

\section{Normal glucose metabolism in PAM haploinsufficient mice To} determine whether reduced expression of Pam in vivo contributes to islet dysfunction and the development of diabetes, we performed metabolic tests on $\mathrm{Pam}^{+/-}$mice. Using antibodies against PAM, amidated IAPP and nonamidated IAPP (Fig. 3a), we found that both PAM levels (Fig. 3b) and enzyme activity were reduced by $50 \%$ (Fig. 3c, d), and non-amidated IAPP was elevated by approximately 2.7 -fold (Fig. 3 b) in $\mathrm{Pam}^{+/-}$islets. Of note, amidated IAPP levels were comparable in $\mathrm{Pam}^{+/-}$ and $\mathrm{Pam}^{+/+}$islets, suggesting that one Pam allele is sufficient for normal peptide amidation to occur, as for hypothalamic thyrotropin releasing hormone (TRH) [30].

When fed an LFD, both male (Fig. 4a, b) and female (Fig. 4e, f) $\mathrm{Pam}^{+/-}$mice and their $\mathrm{Pam}^{+/+}$littermates displayed comparable weight gain and fasting blood glucose levels over a 6 month period. In addition, male (Fig. 4c, d) and female (Fig. 4g, h) $\mathrm{Pam}^{+-}$mice fed an LFD for 8 or 16 weeks displayed similar glucose tolerance compared with $\mathrm{Pam}^{+/+}$mice. Interestingly, despite having comparable adiposity (Fig. 4i, j; also shown as per cent body weight in ESM Fig. 2a, b), when fed an LFD, male $\mathrm{Pam}^{+/-}$mice had slightly improved insulin sensitivity vs $\mathrm{Pam}^{+/+}$ mice (Fig. 4k). No differences were observed in female $\mathrm{Pam}^{+/}$ and $\mathrm{Pam}^{+/+}$LFD-fed-mice (Fig. 41-n and ESM Fig. 2e, f). There were no differences in peripheral organ tissue weights (heart, liver, pancreas, epididymal white adipose tissue and inguinal white adipose tissue) in 32-week-old LFD-fed $\mathrm{Pam}^{+/}$and $\mathrm{Pam}^{+/+}$mice (ESM Fig. 3a-e, males; ESM Fig. 3f-j, females).

PAM haploinsufficiency does not accelerate the development of diet-induced glucose intolerance Next, we challenged $\mathrm{Pam}^{+/-}$and $\mathrm{Pam}^{++}$mice with an HFD to determine whether loss of one PAM allele promotes the development of dietinduced obesity and glucose intolerance. We found that HFD-fed $\mathrm{Pam}^{+/-}$and $\mathrm{Pam}^{+++}$mice had comparable weight gain, fasting blood glucose levels and glucose tolerance over the 6 month diet regimen, in both males (Fig. 5a-d) and females (Fig. 5e-h). Body mass composition, as well as tissue weights, were similar in HFD-fed $\mathrm{Pam}^{+-}$and $\mathrm{Pam}^{+++}$mice (males: Fig. 5i, j, ESM Fig. 2c, d, ESM Fig. 4a-e,; females: Fig. 51, m, ESM Fig. 2 g, h, ESM Fig. 4f-j). The improved insulin sensitivity observed in $\mathrm{Pam}^{+-}$male mice fed an LFD (Fig. 4k) was not present when mice were fed HFD (Fig. 5k). Thus, PAM haploinsufficiency does not accelerate HFDinduced obesity and glucose intolerance.

$\mathrm{PAM}^{+/}$and $\mathrm{PAM}^{+/+}$mice have similar beta cell function To determine whether reduced expression of PAM leads to changes 
in plasma insulin levels, we analysed fasting plasma insulin levels in mice fed an LFD (males, Fig. 6a; females, Fig. 6b) or an HFD (males, Fig. 6c; females, Fig. 6d). Mice fed an HFD displayed moderate, but non-significant, elevation of fasting plasma insulin levels, compatible with diet-induced insulin resistance [31]; however, insulin levels did not differ between $\mathrm{Pam}^{+-}$ and $\mathrm{Pam}^{+/+}$mice. To directly assess the effect of PAM deficiency in islet insulin secretion, we measured glucose-stimulated insulin secretion in isolated $\mathrm{Pam}^{+/-}$and $\mathrm{Pam}^{+/+}$islets. Islets from $\mathrm{Pam}^{+/-}$and $\mathrm{Pam}^{+/+}$mice had comparable glucose-stimulated insulin secretion and insulin content (Fig. 6e, f).

PAM haploinsufficiency does not have an impact on glucose intolerance induced by beta cell hIAPP overexpression The amyloid-forming beta cell peptide hIAPP is a PAM substrate. To understand whether PAM loss affects hIAPP fibril formation and hIAPP-induced beta cell dysfunction and diabetes we next generated $\mathrm{Pam}^{+/-}$ mice with beta cell expression of hIAPP (hIAPP $\mathrm{Tg} / 0$ $\mathrm{Pam}^{+/-}$). While hIAPP introduction induced mild yet statistically significant glucose intolerance in $\mathrm{Pam}^{+/+}$ and $\mathrm{Pam}^{+/-}$mice (Fig. 7a), it did not significantly alter islet PAM levels in $\mathrm{Pam}^{+/+}$mice, nor did it alter the $\sim 50 \%$ reduction of PAM protein typically seen between $\mathrm{Pam}^{+/-}$and $\mathrm{Pam}^{+/+}$mice (Fig. 7b). Overexpression of hIAPP did not appear to alter PAM enzyme activity, since we observed similar PHM and PAL enzyme activity in hIAPP Tg/0 $\mathrm{Pam}^{+/-}$and control hIAPP $0 / 0 \mathrm{Pam}^{+/-}$islets (Fig. 7c, d). As observed in mice with a C57BL/6J background (Fig. 3b), non-amidated IAPP levels were increased in hIAPP $0 / 0 \mathrm{Pam}^{+/-}$compared with hIAPP $0 / 0 \mathrm{Pam}^{+/+}$mouse islets, while levels of amidated IAPP were unchanged among the groups (Fig. 7b), suggesting that PAM levels do not limit the amidation of IAPP.

To determine if PAM haploinsufficiency accelerates the development of hIAPP-induced diabetes, we placed 10week-old hIAPP $\mathrm{Tg} / 0 \mathrm{Pam}^{+/-}$mice and their littermates on a LFD for 24 weeks. While gaining similar weight (Fig. 8a), mice carrying the hIAPP transgene displayed significantly elevated fasting plasma glucose levels (Fig. $8 \mathrm{~b} ; p<0.05)$ and, by the age of 28 weeks, mice had developed mild glucose intolerance (Fig. 8c, 18-weekold mice; Fig. 8d, 28-week-old mice) compared with wild-type littermates, as we have previously observed [32]. The degree of glucose intolerance was comparable between hIAPP $\mathrm{Tg} / 0 \mathrm{Pam}^{+/-}$and hIAPP $\mathrm{Tg} / 0 \mathrm{Pam}^{+/+}$ mice. We also found no differences in insulin sensitivity or body fat composition between groups of mice (Fig. 8eg).

To determine whether Pam expression impacts susceptibility to HFD-induced diabetes in mice with beta cell expression of hIAPP, we fed 10-week-old hIAPP $\mathrm{Tg} / 0 \mathrm{Pam}^{+/-}$mice and their littermates an HFD

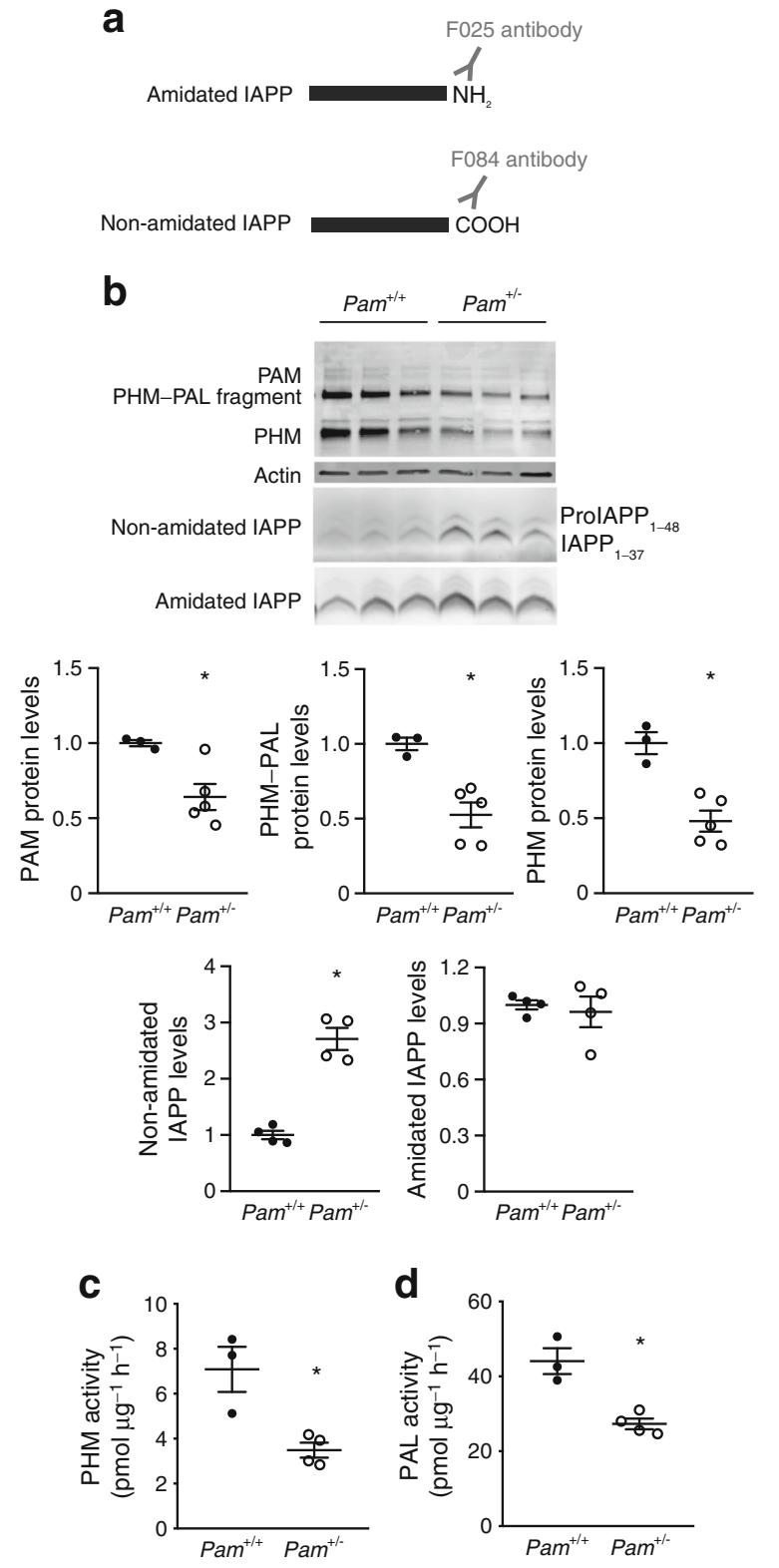

Fig. 3 PAM expression and enzyme activity are reduced in $\mathrm{Pam}^{+/-}$ islets. (a) Schematic representation of antibodies used to detect amidated IAPP (F025) and non-amidated IAPP (F084). (b) Expression levels of PAM, PAM cleavage products (PHM-PAL fragment and PHM domain), and amidated and non-amidated IAPP in islets from 12-16-week-old male $\mathrm{Pam}^{+/-}$and $\mathrm{Pam}^{+/+}$mice were analysed by immunoblotting, using the antibodies listed in (a) and an anti-PAM antibody (JH1761) $(n=3-5)$. (c, d) Islet PHM and PAL enzyme-specific activities were analysed by substrate-based assays $(n=3-4)$. Data are expressed as mean \pm SEM. $* p<0.05$

for 24 weeks. While displaying similar weight gain (Fig. 9a), mice carrying the hIAPP transgene had significantly higher fasting blood glucose levels (Fig. 9b) and a higher incidence of diabetes (fasting blood glucose $>15 \mathrm{mmol} / \mathrm{l}$ for two consecutive measurements) than 
a

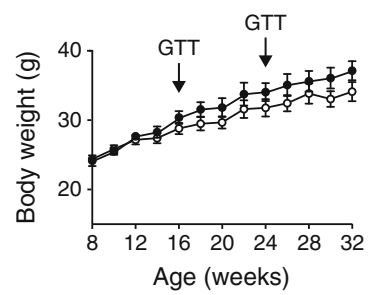

e

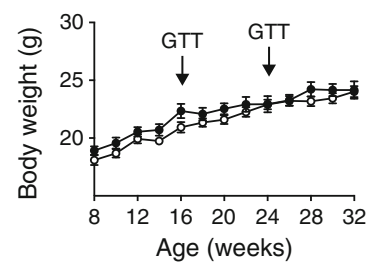

b

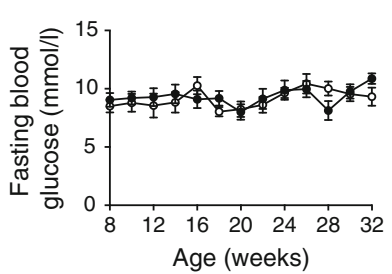

f

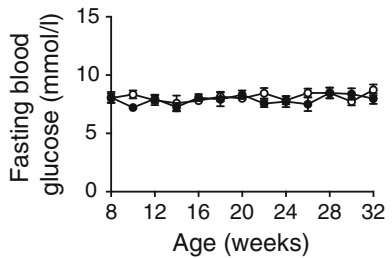

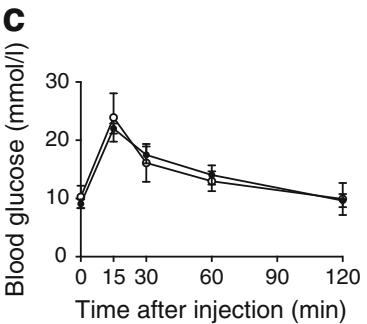

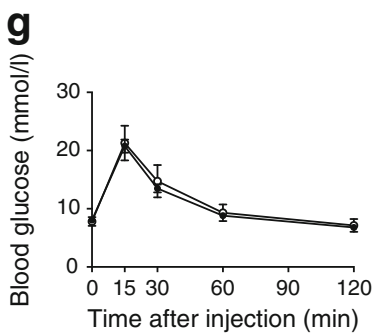

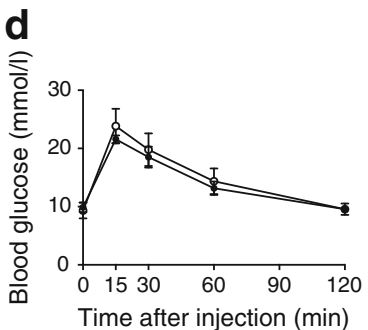

h

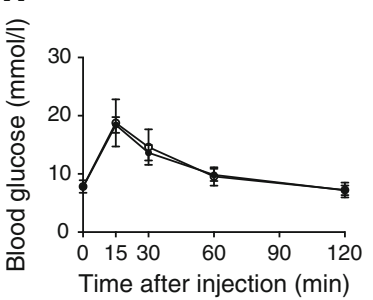

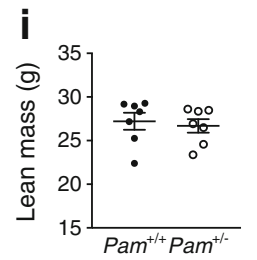
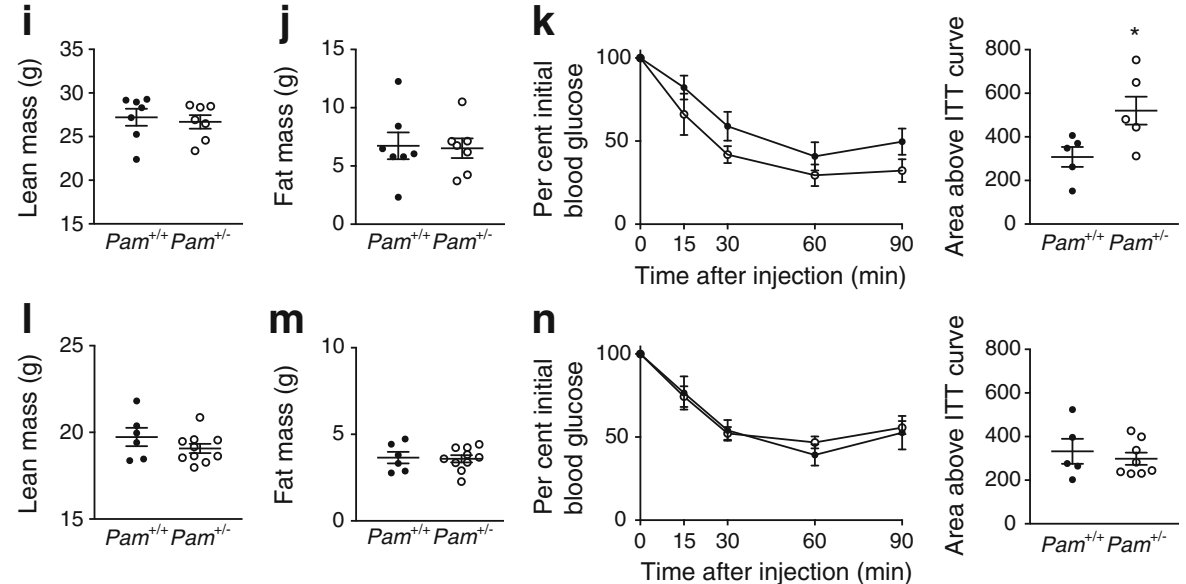

Fig. 4 Metabolic characterisation of $\mathrm{Pam}^{+/-}$and $\mathrm{Pam}^{+/+}$mice. (a-h) Eight-week-old male (a-d) and female (e-h) $\mathrm{Pam}^{+-}$(white circle) and $\mathrm{Pam}^{+/+}$(black circle) littermates were fed a 10\% fat diet (LFD) and body weight (a, e) and $5 \mathrm{~h}$ fasting blood glucose levels $(\mathbf{b}, \mathbf{f})$ were measured every 2 weeks for 24 weeks. IPGTTs were performed at timepoints indicated by black arrows in (a) and (e). In: (a-d), $n=7 ;(\mathbf{e}-\mathbf{h}), n=10$ for $\mathrm{Pam}^{+/-}$and $n=5$ for $\mathrm{Pam}^{+/ 4}$. Following $8(\mathbf{c}, \mathbf{g})$ and $16(\mathbf{d}, \mathbf{h})$ weeks of diet, IPGTTs were performed in $5 \mathrm{~h}$-fasted $\mathrm{Pam}^{+/-}$and $\mathrm{Pam}^{+/+}$mice using a glucose dose of $1.5 \mathrm{~g} / \mathrm{kg}$ body weight. (i-n) At week 20 of the LFD, male (i-k) and female (1-n) $\mathrm{Pam}^{+/-}$and $\mathrm{Pam}^{+/+}$mice were fasted for $5 \mathrm{~h}$ and lean mass $(\mathbf{i}, \mathbf{l})$ and fat mass $(\mathbf{j}, \mathbf{m})$ were analysed. $(\mathbf{k}, \mathbf{n})$ IPITTs were performed using an insulin dose of $1.5 \mathrm{IU} / \mathrm{kg}$ lean mass. In (i-n), $n=5$ 10. Data are expressed as mean \pm SEM non-transgenic littermates (Fig. 9c). There was no significant difference in glucose tolerance, insulin sensitivity or body mass composition between hIAPP $\mathrm{Tg} / 0$ $\mathrm{Pam}^{+/-}$and hIAPP Tg/0 $\mathrm{Pam}^{+/+}$mice (Fig. 9d-h).

PAM haploinsufficiency does not impact hIAPP-induced beta cell dysfunction and islet amyloid formation hIAPP $\mathrm{Tg} / 0$ $\mathrm{Pam}^{+/-}$mice displayed similar fasting plasma insulin levels compared with their littermates (Fig. 10a, b, 16 weeks and 24 weeks post-LFD, respectively; Fig. $10 \mathrm{c}, \mathrm{d}, 16$ weeks and 24 weeks post-HFD, respectively). To gain insight into whether PAM deficiency leads to changes in insulin secretion or amyloid formation, we also studied islets ex vivo. Islets from hIAPP $\mathrm{Tg} / 0$ $\mathrm{Pam}^{+/-}$and hIAPP Tg/0 $\mathrm{Pam}^{+/+}$mice released similar amounts of insulin in response to glucose and had comparable insulin content (Fig. 10e, f). Following culture in high $(25 \mathrm{mmol} / \mathrm{l})$ glucose medium for 3 or 7 days, thioflavin $\mathrm{S}^{+}$islet amyloid [22] was readily observed in both hIAPP Tg/0 $\mathrm{Pam}^{+-}$and hIAPP $\mathrm{Tg} / 0$ $\mathrm{Pam}^{+/+}$islets (Fig. $10 \mathrm{~g}, \mathrm{~h}$ ). hIAPP Tg/0 $\mathrm{Pam}^{+/-}$and hIAPP $\mathrm{Tg} / 0 \mathrm{Pam}^{+/+}$islets developed similar amyloid burden at both time points (Fig. 10i, j). These data suggest that haploinsufficiency of PAM does not alter insulin secretion or amyloid formation in hIAPPexpressing mouse islets. 
a

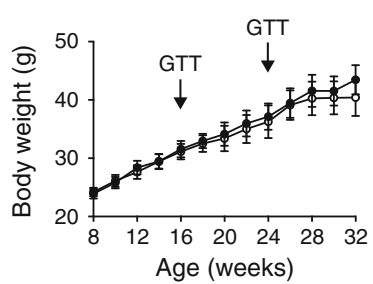

e

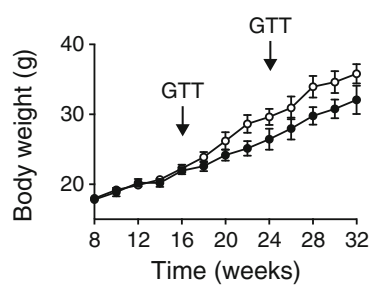

b

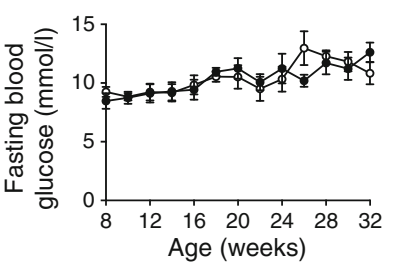

f

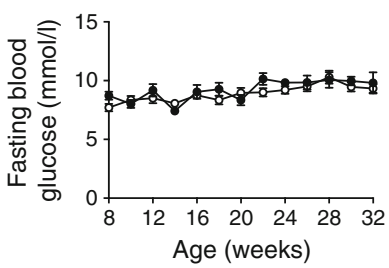

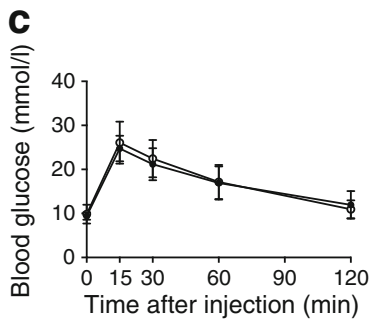

d
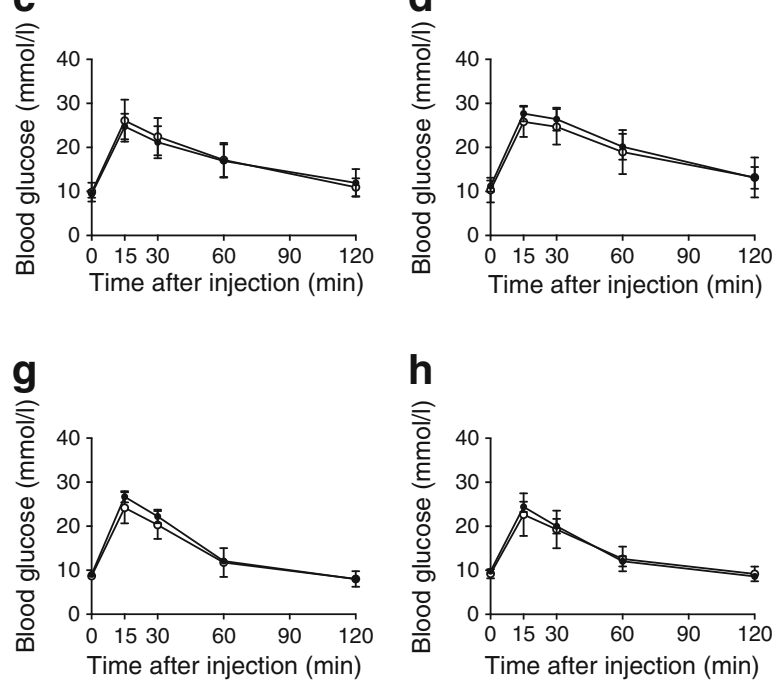
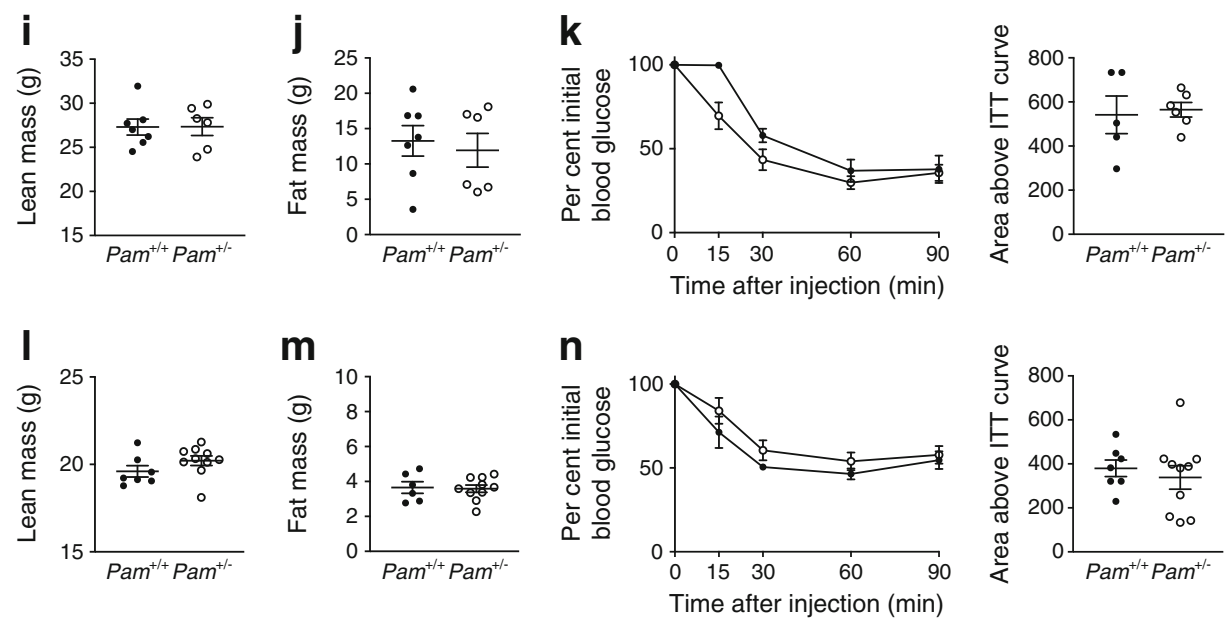

Fig. 5 Metabolic characterisation of HFD-challenged $\mathrm{Pam}^{+-}$and $\mathrm{Pam}^{+/+}$mice. (a-h) Eight-week-old male (a-d) and female (e-h) $\mathrm{Pam}^{+/-}$ (white circle) and $\mathrm{Pam}^{+/+}$(black circle) mice were fed with a $45 \%$ fat diet (HFD) and body weight (a, e) and $5 \mathrm{~h}$ fasting blood glucose levels (b, f) were measured every 2 weeks for 24 weeks. IPGTTs were performed at timepoints indicated by black arrows in (a) and (e). In: (a-d) $n=7 ;(\mathbf{e}-\mathbf{h})$ $n=10$. At $8(\mathbf{c}, \mathbf{g})$ and $16(\mathbf{d}, \mathbf{h})$ weeks of HFD, IPGTTs were performed in
$5 \mathrm{~h}$-fasted $\mathrm{Pam}^{+/-}$and $\mathrm{Pam}^{+/+}$mice using a glucose dose of $1.5 \mathrm{~g} / \mathrm{kg}$ body weight. (i-n) After 20 weeks of HFD-challenge, male (i-k) and female ( $\mathbf{1}$ n) $\mathrm{Pam}^{+/-}$and $\mathrm{Pam}^{+/+}$mice were fasted for $5 \mathrm{~h}$ and lean mass (i, l) and fat mass $(\mathbf{j}, \mathbf{m})$ were analysed. (k, n) IPITTs were performed using an insulin dose of $1 \mathrm{IU} / \mathrm{kg}$ lean mass. In (i-n), $n=5-10$. Data are expressed as mean \pm SEM

associated with hypertension in a Korean population [33] and the $P A M$ rs35658696 SNP is associated with reduced insulinogenic index [6]. Both PAM rs35658696 and rs78408340 variants are associated with increased type 2 diabetes risk [7, 8]. Importantly, the missense variant rs35658696 (encoding p.Asp563Gly) of PAM has a minor allele frequency close to $5 \%$, suggesting that approximately one in ten people are PAM-variant carriers. PAM may play a direct role in regulating insulin secretion, because islets from carriers of the PAM variant rs35658696 have modestly reduced glucose-stimulated insulin secretion [9]. In the same report, the authors suggested that the mutation of PAM likely 
a

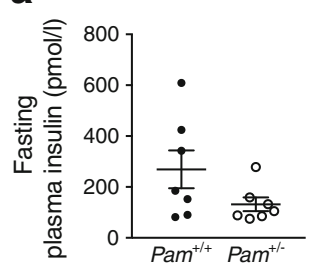

b

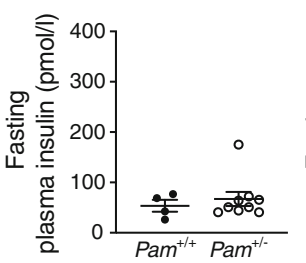

C

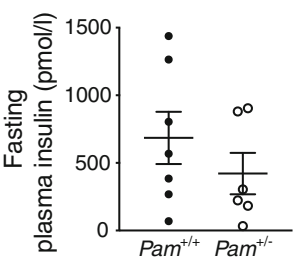

d

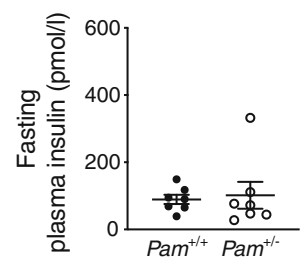

e

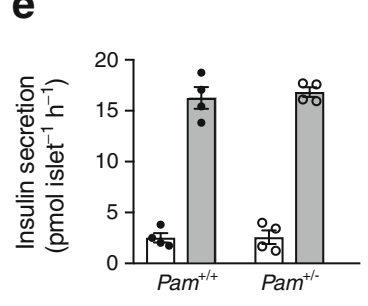

f

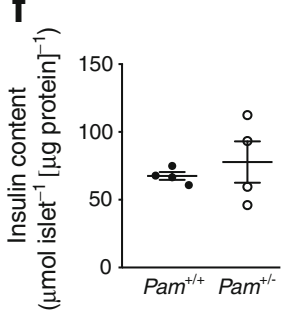

Fig. 6 Plasma and islets insulin levels in $\mathrm{Pam}^{+/-}$and $\mathrm{Pam}^{+/+}$mice. (ad) Fasting plasma insulin levels were measured in blood collected from male (a, c) and female $(\mathbf{b}, \mathbf{d}) \mathrm{Pam}^{+/-}$and $\mathrm{Pam}^{+/+}$mice kept for 24 weeks on a $10 \%$ fat diet (LFD; $\mathbf{a}, \mathbf{b}, n=4-9$ ), or a $45 \%$ fat diet (HFD; $\mathbf{c}, \mathbf{d} ; n=6-$ 7). In vitro insulin secretion (e) and insulin content (f) assays were performed using islets collected from 12-week-old chow-fed $\mathrm{Pam}^{+-}$ and $\mathrm{Pam}^{+/+}$mice. Islets were treated with $1.67 \mathrm{mmol} / 1$ glucose for $1 \mathrm{~h}$, followed by $16.7 \mathrm{mmol} / 1$ glucose for $1 \mathrm{~h}$. Insulin immunoreactivity in the incubation medium and islet lysates was measured by ELISA $(n=4)$. Data are expressed as mean \pm SEM leads to loss of protein expression (rs78408340) or reduced enzyme activity (rs35658696). In order to elucidate the pathophysiological mechanism underlying PAM deficiency and the development of diabetes, we studied Pam whole-body heterozygous knockout mice (to mirror the partial loss of PAM activity in all tissues, analogous to human PAM-variant carriers [9]). We found that $\mathrm{Pam}^{+-}$mice have similar glucose tolerance compared with $\mathrm{Pam}^{+/+}$littermates, suggesting that haploinsufficiency of PAM does not affect whole-body glucose utilisation. Although we observed no differences in body weight between $\mathrm{Pam}^{+/-}$and $\mathrm{Pam}^{+/ 4}$ mice, male (but not female) $\mathrm{Pam}^{+/}$mice fed an LFD had modestly improved insulin sensitivity. PAM may play a role in the regulation of insulin sensitivity through amidation of neuropeptide substrates, including $\alpha$-melanocyte-stimulating hormone $(\alpha \mathrm{MSH}), \mathrm{CCK}, \mathrm{NPY}$ or chromogranin A [34-38].

We observed no difference in beta cell function in vivo or in isolated islets in mice that were haploinsufficient for PAM, as compared with controls. While Thomsen et al recently described a mild decrease in glucose-stimulated insulin secretion in human islets from donors that were carriers of the PAM variant rs35658696, and silencing $P A M$ in EndoC- $\beta \mathrm{H} 1$ cells led to mild reduction of insulin content/secretion [9], our data in mice would suggest that the modest impairment in insulin secretion and increased type 2 diabetes risk in PAM-variant carriers is unlikely to be explained by reduced PAM activity. Species differences in glucose metabolism and the capacity of islets to adapt to environmental challenges could also contribute to the lack of metabolic phenotype in $\mathrm{Pam}^{+/-}$mice. C57BL/6 mice, used in most metabolic studies (including this study), do not develop diabetes spontaneously and, even on an HFD, rodent beta cells have higher proliferative capacity to compensate for increased metabolic demands. In contrast, in humans type 2 diabetes is a polygenic disorder that often develops in middle age, when metabolic and inflammatory stresses may increase and islets have reduced tissue remodelling capacity. In this setting, $P A M$ polymorphism carriers may display insulin secretion defects that confer increased type 2 diabetes risk.

Thomsen et al proposed that deficient amidation of a secretory granule protein, chromogranin A, might be one contributor to the observed beta cell dysfunction [9]. However, the precise mechanism linking PAM to beta cell function remains an open question. We found that islets from $\mathrm{Pam}^{+-}$mice contained amounts of amidated IAPP similar to that in islets of $\mathrm{Pam}^{+/+}$mice, suggesting that one copy of Pam is sufficient to catalyse normal levels of peptide amidation. Levels of nonamidated IAPP immunoreactivity, which are much lower than levels of amidated IAPP, were elevated in $\mathrm{Pam}^{+-}$mice (Fig. $3 b)$. In agreement with our findings, $\mathrm{Pam}^{+/-}$mice have been shown to be able to amidate CCK and TRH normally in the hypothalamus $[2,30]$. Nonetheless, it is unclear whether PAMvariant carriers produce amidated peptides at physiologically appropriate levels. In aggregate, our data suggest that PAM haploinsufficiency alone seems unlikely to explain 


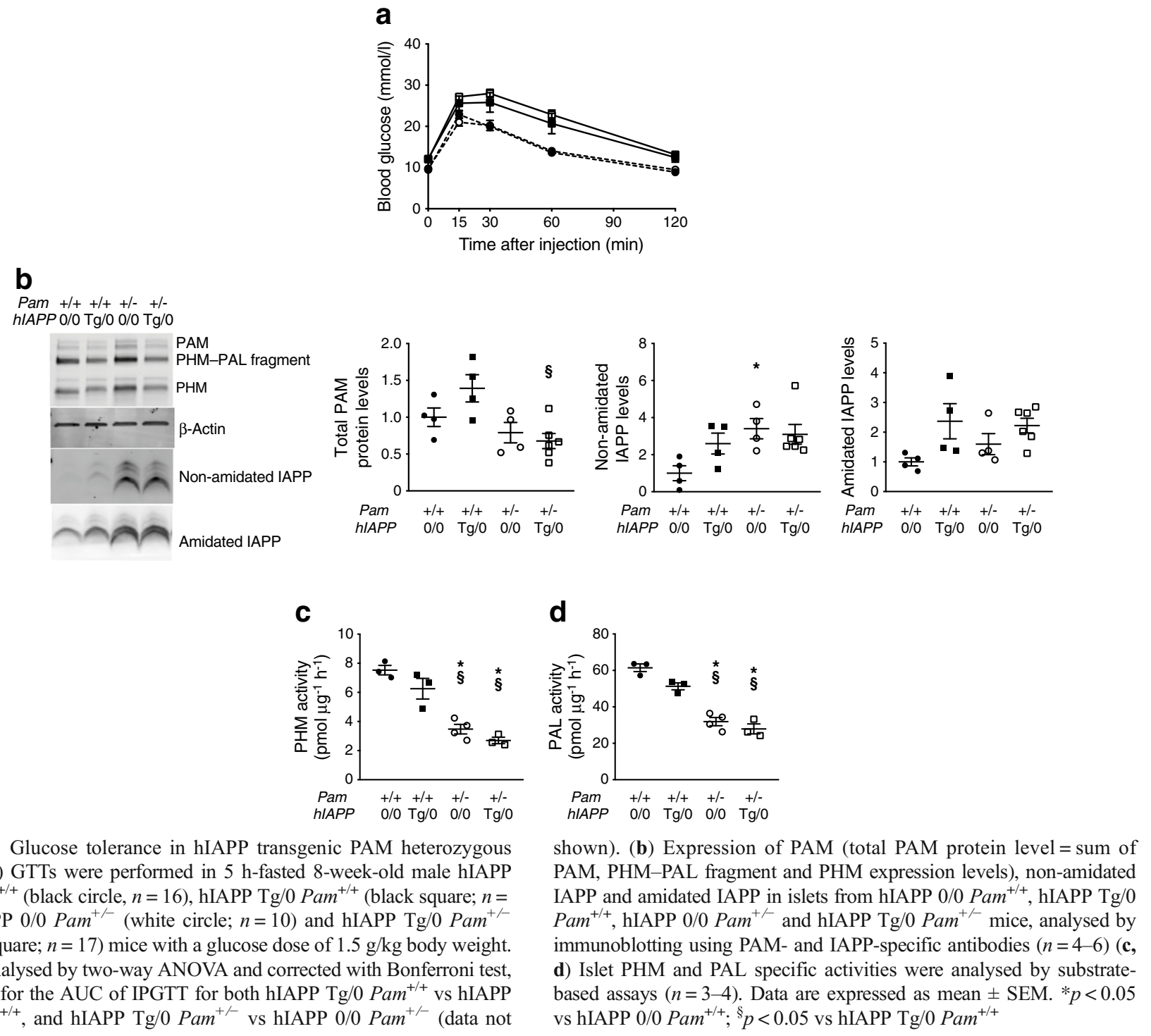

susceptibility to type 2 diabetes and beta cell dysfunction, even in the presence of the increased metabolic and secretory stresses of obesity.

Amyloid deposition in pancreatic islets is a prominent feature of type 2 diabetes [39]. To determine whether PAM haploinsufficiency has an impact on islet amyloid formation and diabetes susceptibility, we crossed mice with beta cell expression of hIAPP with $\mathrm{Pam}^{+/-}$mice. IAPP is a PAM substrate and synthetic hIAPP variants with a free (nonamidated) $\mathrm{COOH}$-terminus aggregate more slowly than COOH-terminally amidated forms $[17,40]$. We hypothesised that impaired amidation of hIAPP in $\mathrm{Pam}^{+/-}$mice may lead to production of hIAPP forms with altered fibril-forming kinetics,

morphology and cytotoxicity [41]. Both hIAPP Tg/0 $\mathrm{Pam}^{+-}$ and hIAPP $\mathrm{Tg} / 0 \mathrm{Pam}^{+/+}$mice developed hyperglycaemia and diabetes upon HFD challenge, yet insulin sensitivity, glucose tolerance and plasma insulin levels were comparable, suggesting that reduced expression of PAM is insufficient to promote hIAPP-induced islet failure and diabetes. It is plausible that any mild impact of PAM haploinsufficiency on glucose tolerance was masked by the more marked glucose intolerance in mice expressing the hIAPP transgene. Since non-amidated hIAPP immunoreactivity is detectable in islets of hIAPP Tg/0 $\mathrm{Pam}^{+/+}$ mice and haploinsufficiency of PAM does not further increase non-amidated hIAPP levels (Fig. 7a), it is possible that PAM cannot fully amidate hIAPP under conditions of 

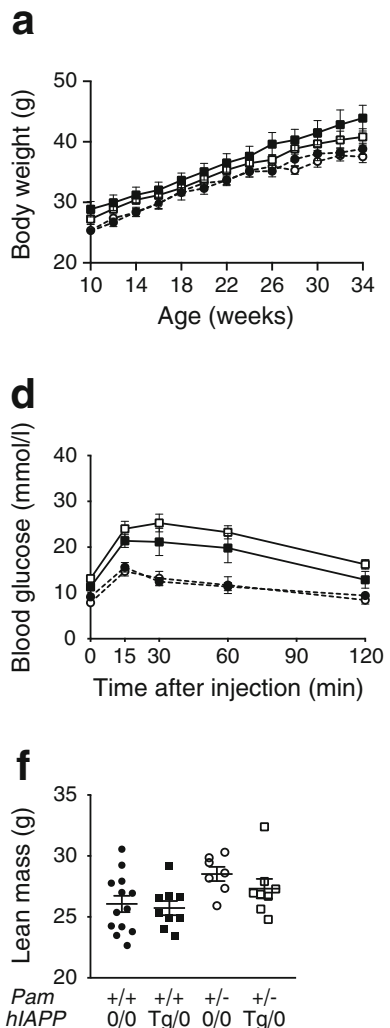
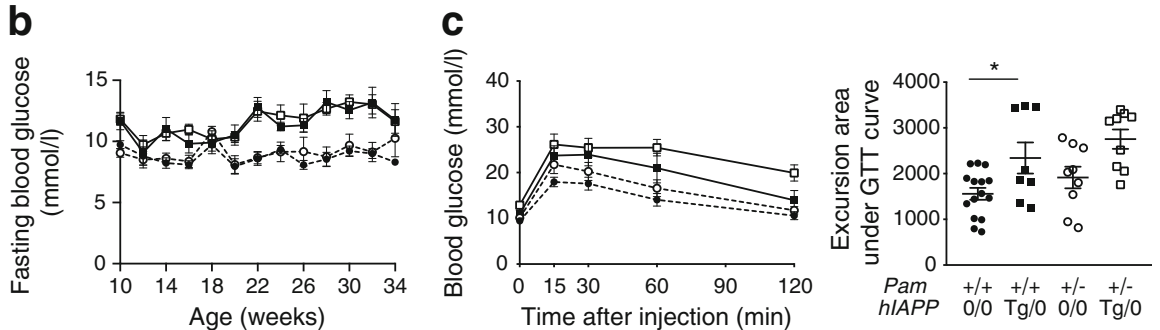
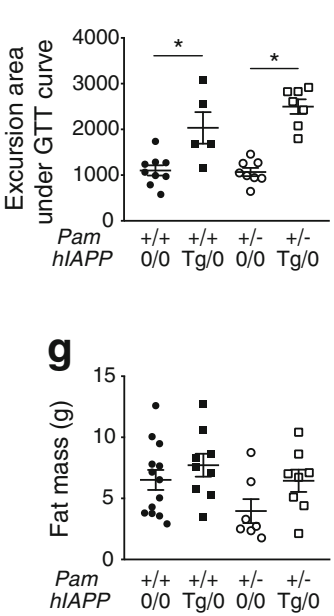

Fig. 8 Metabolic characterisation of hIAPP transgenic PAM heterozygous mice. (a, b) Ten-week-old male hIAPP 0/0 $\mathrm{Pam}^{+/+}$(black circle, dashed line; $n=15$ ), hIAPP Tg $/ 0 \mathrm{Pam}^{+/+}$(black square; $n=13$ ), hIAPP $0 / 0 \mathrm{Pam}^{+/-}$(white circle, dashed line; $n=9$ ), and hIAPP Tg/0 $\mathrm{Pam}^{+/}$(white square; $n=10$ ) mice were fed a $10 \%$ fat diet (LFD) and body weight (a) and $5 \mathrm{~h}$ fasting blood glucose levels (b) were monitored every 2 weeks. When analysed by twoway ANOVA and corrected with Bonferroni test, $p<0.05$ for the AUC of blood glucose for both hIAPP Tg/0 $\mathrm{Pam}^{+/+}$vs hIAPP $0 / 0 \mathrm{Pam}^{+/+}$, and hIAPP $\mathrm{Tg} / 0 \mathrm{Pam}^{+/}$vs hIAPP 0/0 $\mathrm{Pam}^{+/}$(data not shown). (c, d) After 8 (c) and 20

supraphysiological transgenic expression, or that the conditions for optimal PAM activity (i.e. copper or ascorbate concentration and $\mathrm{pH}$ ) are not present in granules of hIAPPexpressing mice. Future experiments using models with more closely related physiological expression of hIAPP (i.e. hIAPP knockin mice [42]), or exposing islets to synthetic hIAPP peptides ex vivo, may provide insight into the impact of amidation, if any, on the toxicity of hIAPP.

While deleting one copy of Pam in mice did not result in significant metabolic abnormalities, the potential importance of PAM in modulating insulin secretion in humans (and in mice) should not be overlooked. Mutation or small hairpin RNA-mediated silencing of $P A M$ leads to a modest reduction in glucose-stimulated insulin secretion from human islet cells [9]. In the present study, we found that PAM expression is sensitive to

(d) weeks of LFD, IPGTT was performed in $5 \mathrm{~h}$-fasted hIAPP Tg/0 $\mathrm{Pam}^{+/}$ and littermate mice using a glucose dose of $1.5 \mathrm{~g} / \mathrm{kg}$ body weight and area under the GTT curve was determined. In: (c) $n=8-15$; (d) $n=5-9$. (e) After 12 weeks of LFD, IPITTs were performed in 5 h-fasted hIAPP Tg/0 $\mathrm{Pam}^{+-}$ and littermate mice using an insulin dose of $1 \mathrm{IU} / \mathrm{kg}$ lean mass (hIAPP 0/0 $\mathrm{Pam}^{+/+}, n=12$; hIAPP Tg $/ 0 \mathrm{Pam}^{+/+}, n=8$; hIAPP $0 / 0 \mathrm{Pam}^{+/}, n=7$; hIAPP $\left.\mathrm{Tg} / 0 \mathrm{Pam}^{+/}, n=8\right)$. (f, g) Lean (f) and fat (g) mass compositions were analysed $(n=7-13)$. Data are expressed as mean \pm SEM. $* p<0.05$

islet stressors. Whereas high glucose increased Pam expression in isolated islets, chronic metabolic stress induced by HFD, as well as ER- or cytokine-induced stress, reduced Pam transcript levels. Our data suggest that PAM expression closely reflects the secretory burden and health of beta cells. In neuroendocrine cells, it has also been reported that peptide amidation is impaired under conditions of hypoxia, and PAMmediated peptide amidation may act as an oxygen sensing system [13]. Because hypoxia is deleterious to islets, restoring PAM may potentially reduce loss of islets in pre- and post-transplant settings in type 1 diabetes, when hypoxia is thought to be present.

In summary, we found that PAM haploinsufficiency does not accelerate development of diet- or hIAPP transgene-induced obesity and diabetes. We further showed 

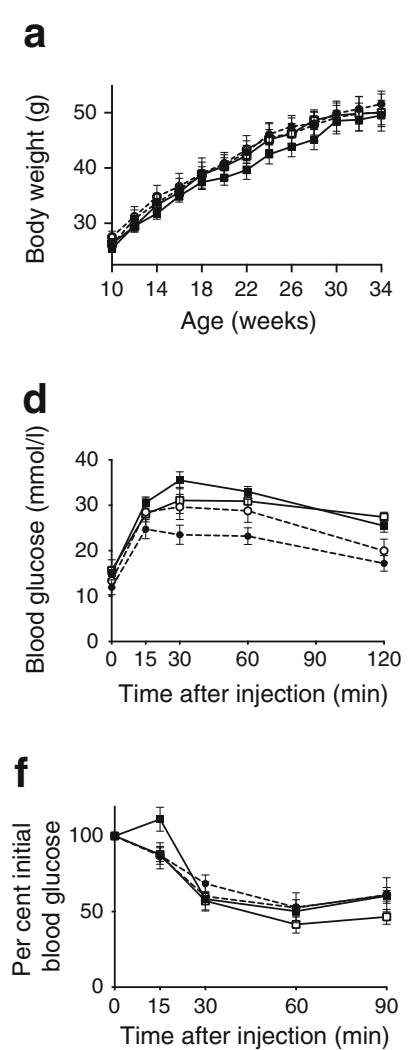
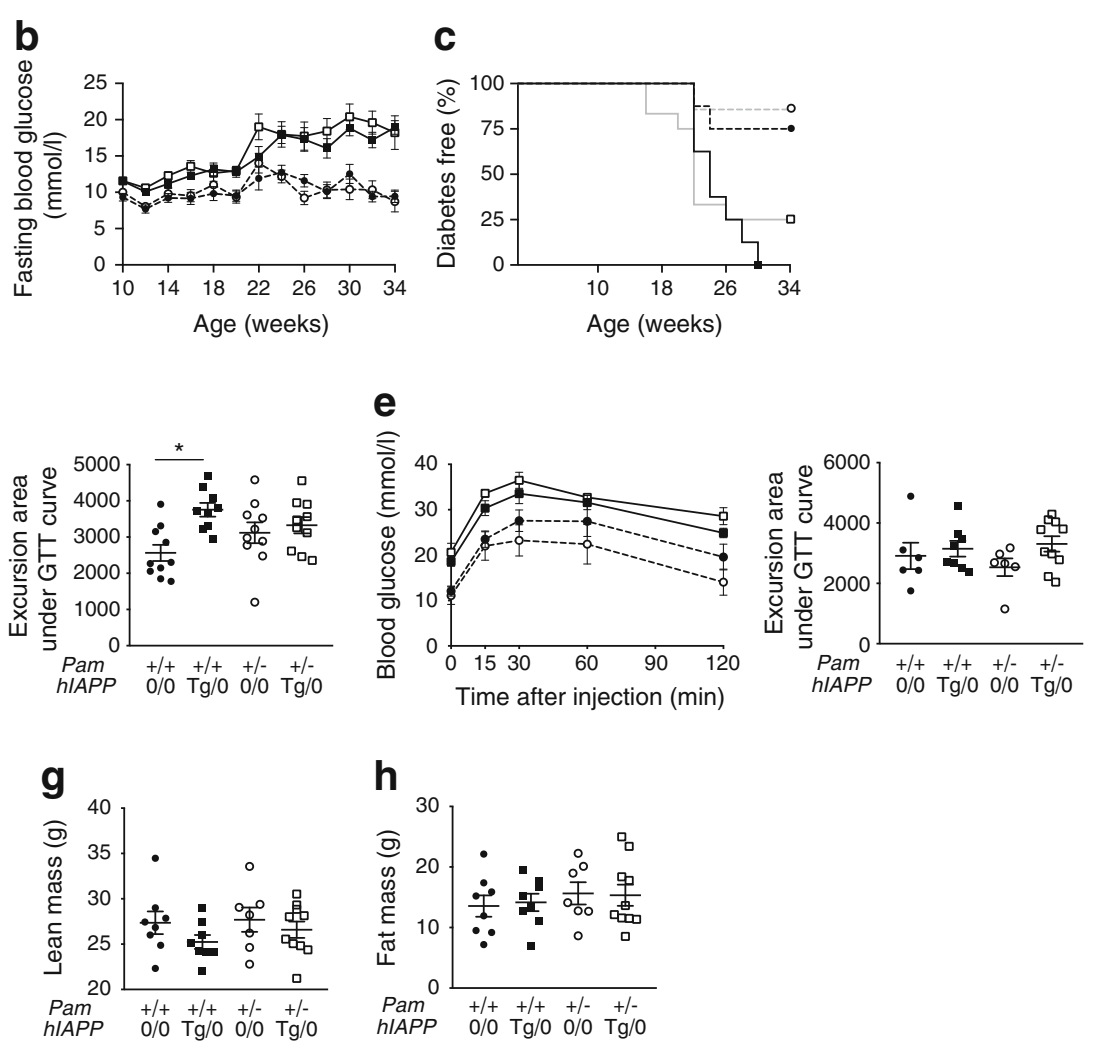

Fig. 9 Metabolic characterisation of HFD-fed hIAPP transgenic PAM heterozygous mice. Ten-week-old male hIAPP 0/0 $\mathrm{Pam}^{+/+}$(black circle, dashed line), hIAPP Tg/0 $\mathrm{Pam}^{+/+}$(black square), hIAPP 0/0 $\mathrm{Pam}^{+/}$(white circle, dashed line) and hIAPP Tg/0 $\mathrm{Pam}^{+\digamma}$ (white square) mice were fed an HFD (45\% fat diet). (a - c) Body weight (a) and $5 \mathrm{~h}$ fasting blood glucose levels (b) were monitored every 2 weeks $(n=10)$, and diabetes-free survival rates were analysed (c) (diabetes was defined as two consecutive fasting blood glucose measurements $>15 \mathrm{mmol} / \mathrm{l})$. In (b) and (c), $p<0.05$ for hIAPP Tg/0 $\mathrm{Pam}^{+/+} /$ $\mathrm{Pam}^{+/}$mice vs hIAPP 0/0 $\mathrm{Pam}^{+/+} / \mathrm{Pam}^{+/}$, analysed by two-way ANOVA

that 50\% PAM deficiency in mouse islets does not have a major impact on peptide amidation, beta cell function or islet amyloid deposition. PAM expression is, however, highly subject to the changes in the islet milieu seen in diabetes, including elevated glucose and the presence of ER or cytokine stress. This study contributes to our understanding of the role of PAM polymorphisms in type 2 diabetes. We showed that PAM haploinsufficiency alone is insufficient to trigger islet dysfunction or glucose intolerance in mice, implying that other mechanisms in addition to PAM haploinsufficiency may be involved in conferring type 2 diabetes risk in humans. Further studies are needed to understand how changes in PAM expression or PAM variants may affect beta cell function and whether restoring PAM expression or activity may be a treatment strategy for improving islet function in diabetes. and corrected with Bonferroni test or logrank test, respectively. (d, e) After 8 (d) and 20 (e) weeks of HFD, IPGTTs were performed in $5 \mathrm{~h}$-fasted hIAPP Tg/0 $\mathrm{Pam}^{+\digamma}$ and littermate mice using a glucose dose of $0.75 \mathrm{~g} / \mathrm{kg}$ body weight, and area under the GTT curve was analysed. In: (d) $n=9-10$; (e) $n=6-10$. (f) After 12 weeks of HFD, IPITTs were performed in 5 h-fasted hIAPP Tg/0 $\mathrm{Pam}^{+-}$ and littermate mice using an insulin dose of $1 \mathrm{IU} / \mathrm{kg}$ lean mass (hIAPP 0/0 $\mathrm{Pam}^{+/+}, n=7$; hIAPP Tg $/ 0 \mathrm{Pam}^{+/+}, n=8$; hIAPP 0/0 $\mathrm{Pam}^{+/}, n=5$; hIAPP Tg/ $\left.0 \mathrm{Pam}^{++}, n=7\right)$. (g, h) Lean (g) and fat (h) mass composition were analysed $(n=7-10)$. Data are expressed as mean \pm SEM. $* p<0.05$
Acknowledgements We thank G. Soukhatcheva, D. Dai, M. Komba and K. Zhu (Department of Surgery, University of British Columbia, Vancouver, BC, Canada) for the assistance with mouse metabolic tests and islet isolation. We also wish to acknowledge K. Zhu and J. Wang (BC Children's Hospital Research Institute, Vancouver, BC, Canada) for help with microscope image acquisition.

Data availability The datasets generated and analysed during the current study are available from the corresponding author upon request.

Funding This work was supported by grants from the Canadian Institutes of Health Research (PJT - 153156) and JDRF (3-SRA-2014-39-Q-R) (to CBV), a grant from the National Institutes of Health DK-32949 (to BAE and REM) and a postdoctoral fellowship from JDRF International 3PDF-2017-373-A-N (to Y-CC).

Duality of interest The authors declare that there is no duality of interest associated with this manuscript. 

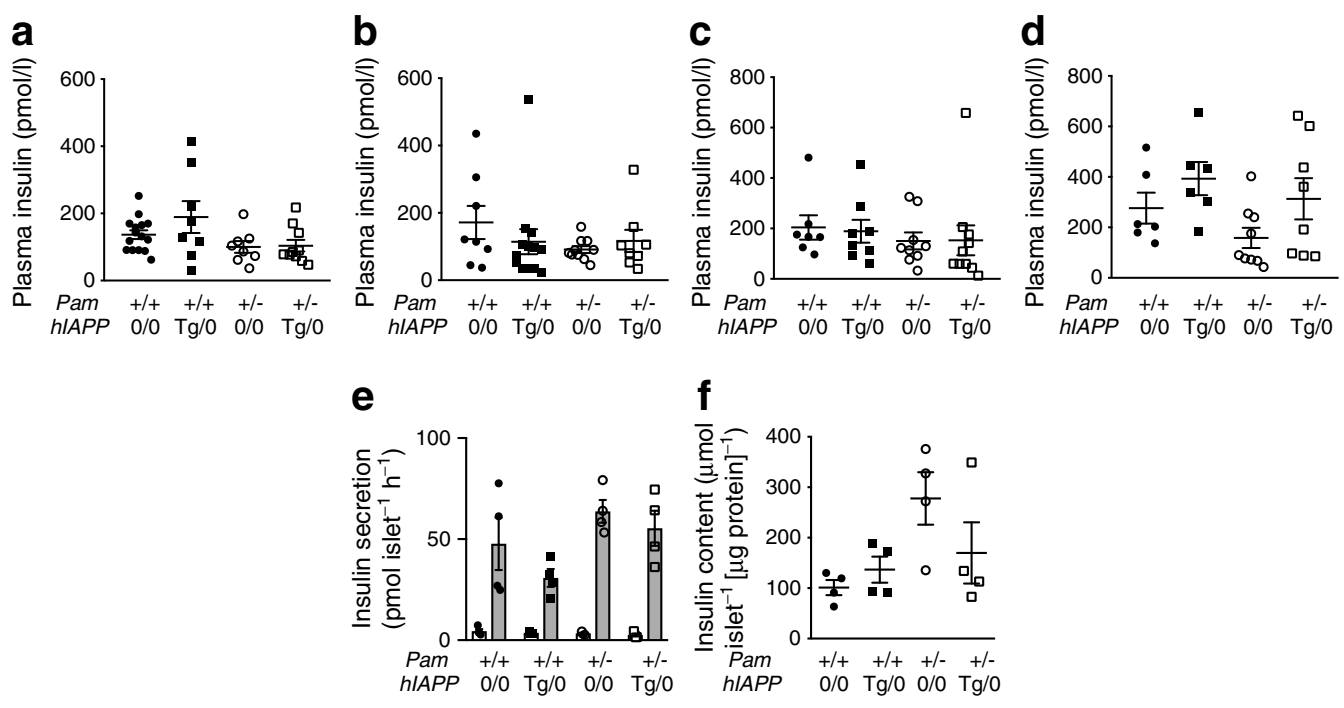

9

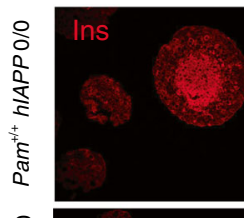

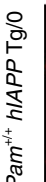
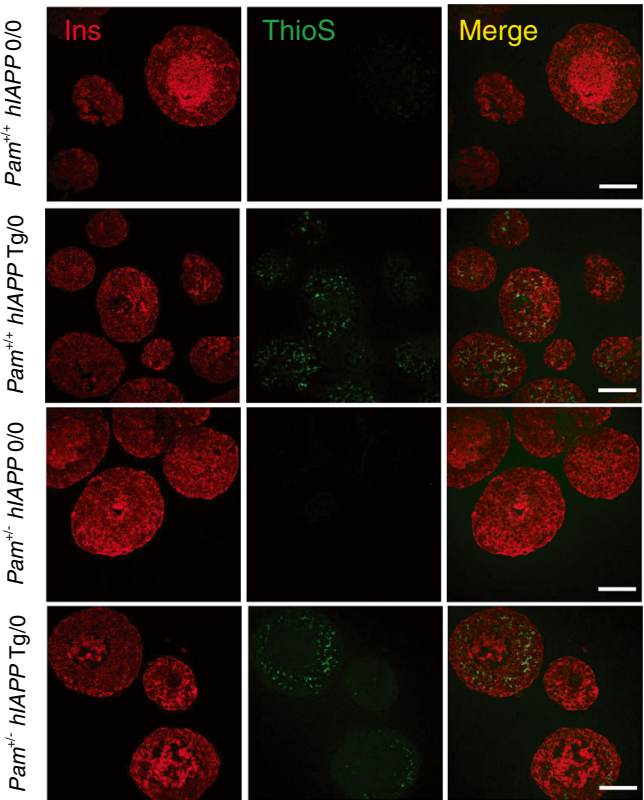

Fig. 10 Beta cell function and islet amyloid deposition in hIAPP transgenic PAM heterozygous mice. (a-d) Plasma insulin levels were determined by ELISA in hIAPP 0/0 $\mathrm{Pam}^{+/+}$, hIAPP Tg/0 $\mathrm{Pam}^{+/+}$, hIAPP 0/0 $\mathrm{Pam}^{+/}$and hIAPP Tg/0 $\mathrm{Pam}^{+/}$male mice fed a diet with $10 \%$ fat for 16 weeks (a) or 24 weeks (b) $(n=8-15)$ or $45 \%$ fat for 16 weeks (c) or 24 weeks (d) $(n=6-10)$. (e, f) In vitro glucose-stimulated insulin secretion (e) and insulin content (f) were measured using islets collected from h
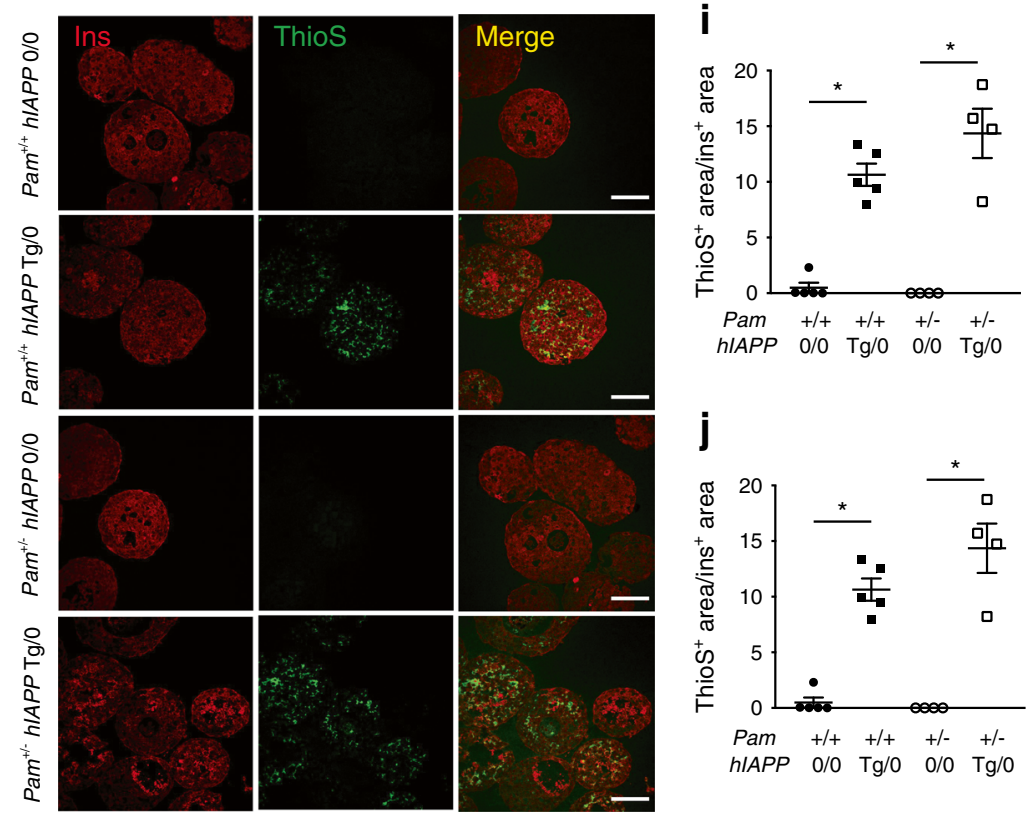

Contribution statement Y-CC conceived and designed the experiments, acquired and analysed the data, and drafted the manuscript. REM, BAE and $\mathrm{BGH}$ provided critical reagents, participated in data collection and interpretation, and edited the manuscript. TAC and JEP provided critical reagents, participated in data interpretation and reviewed the manuscript. CBV contributed to conception and design, interpreted the data and drafted the manuscript. All authors have approved the final version for publication. $\mathrm{CBV}$ is the guarantor of this work and, as such, is responsible for the integrity of the work as a whole.
hIAPP Tg/0 $\mathrm{Pam}^{+/-}$and littermate mice $(n=4)$. $(\mathbf{g}-\mathbf{j})$ Islets isolated from 16-week-old chow-fed female hIAPP Tg/0 $\mathrm{Pam}^{+/-}$and littermate mice were cultured in $25 \mathrm{mmol} / \mathrm{l}$ glucose for 3 days $(\mathbf{g}, \mathbf{i})$ or 7 days $(\mathbf{h}, \mathbf{j})$. Islet amyloid severity was determined as thioflavin $\mathrm{S}^{+}$area/insulin ${ }^{+}$area $(\mathbf{i}, \mathbf{j}$; $n=4-5$ ). Scale bars, $75 \mu \mathrm{m}$. Data are expressed as mean \pm SEM. $* p<0.05$. Ins, insulin; ThioS, thioflavin $\mathrm{S}$

\section{References}

1. Kumar D, Mains RE, Eipper BA (2016) 60 years of POMC: from POMC and $\alpha-\mathrm{MSH}$ to PAM, molecular oxygen, copper, and vitamin C. J Mol Endocrinol 56(4):T63-T76. https://doi.org/10.1530/ JME-15-0266

2. Czyzyk TA, Ning Y, Hsu M-S et al (2005) Deletion of peptide amidation enzymatic activity leads to edema and embryonic 
lethality in the mouse. Dev Biol 287(2):301-313. https://doi.org/10. 1016/j.ydbio.2005.09.001

3. Kumar D, Strenkert D, Patel-King RS et al (2017) A bioactive peptide amidating enzyme is required for ciliogenesis. eLife 6 : e25728. https://doi.org/10.7554/eLife.25728

4. Kumar D, Thomason RT, Yankova M et al (2018) Microvillar and ciliary defects in zebrafish lacking an actin-binding bioactive peptide amidating enzyme. Sci Rep 8(1):4547. https://doi.org/10. 1038/s41598-018-22732-9

5. Bousquet-Moore D, Mains RE, Eipper BA (2010) PAM and copper - a gene/nutrient interaction critical to nervous system function. J Neurosci Res 88(12):2535-2545. https://doi.org/10.1002/jnr.22404

6. Huyghe JR, Jackson AU, Fogarty MP et al (2013) Exome array analysis identifies new loci and low-frequency variants influencing insulin processing and secretion. Nat Genet 45(2):197-201. https:// doi.org/10.1038/ng.2507

7. Steinthorsdottir V, Thorleifsson G, Sulem P et al (2014) Identification of low-frequency and rare sequence variants associated with elevated or reduced risk of type 2 diabetes. Nat Genet 46(3):294-298. https://doi.org/10.1038/ng.2882

8. Fuchsberger C, Flannick J, Teslovich TM et al (2016) The genetic architecture of type 2 diabetes. Nature 536(7614):41-47. https:// doi.org/10.1038/nature18642

9. Thomsen SK, Raimondo A, Hastoy B et al (2018) Type 2 diabetes risk alleles in PAM impact insulin release from human pancreatic $\beta$-cells. Nat Genet 50(8):1122-1131. https://doi.org/10.1038/ s41588-018-0173-1

10. Mahajan A, Wessel J, Willems SM et al (2018) Refining the accuracy of validated target identification through coding variant finemapping in type 2 diabetes. Nat Genet 50(4):559-571. https://doi. org/10.1038/s41588-018-0084-1

11. Prigge ST, Kolhekar AS, Eipper BA, Mains RE, Amzel LM (1997) Amidation of bioactive peptides: the structure of peptidylglycine alpha-hydroxylating monooxygenase. Science 278(5341):13001305. https://doi.org/10.1126/science.278.5341.1300

12. Chufán EE, De M, Eipper BA, Mains RE, Amzel LM (2009) Amidation of bioactive peptides: the structure of the lyase domain of the amidating enzyme. Structure 1993 17(7):965-973. https:// doi.org/10.1016/j.str.2009.05.008

13. Simpson PD, Eipper BA, Katz MJ et al (2015) Striking oxygen sensitivity of the peptidylglycine $\alpha$-amidating monooxygenase (PAM) in neuroendocrine cells. J Biol Chem J 290(41):2489124901. https://doi.org/10.1074/jbc.M115.667246

14. Akter R, Cao P, Noor H et al (2016) Islet amyloid polypeptide: structure, function, and pathophysiology. J Diabetes Res 2016: 2798269. https://doi.org/10.1155/2016/2798269

15. Westwell-Roper CY, Ehses JA, Verchere CB (2014) Resident macrophages mediate islet amyloid polypeptide-induced islet IL$1 \beta$ production and $\beta$-cell dysfunction. Diabetes 63(5):1698-1711. https://doi.org/10.2337/db13-0863

16. Eguchi K, Nagai R (2017) Islet inflammation in type 2 diabetes and physiology. J Clin Invest 127(1):14-23. https://doi.org/10.1172/ JCI88877

17. Tran L, Ha-Duong T (2016) Effect of post-translational amidation on islet amyloid polypeptide conformational ensemble: implications for its aggregation early steps. Int J Mol Sci 17(11):1896. https://doi.org/10.3390/ijms17111896

18. Campbell-Thompson M, Wasserfall C, Kaddis J et al (2012) Network for Pancreatic Organ Donors with Diabetes (nPOD): developing a tissue biobank for type 1 diabetes. Diabetes Metab Res Rev 28(7):608-617. https://doi.org/10.1002/dmrr.2316

19. Lyon J, Manning Fox JE, Spigelman AF et al (2016) Researchfocused isolation of human islets from donors with and without diabetes at the Alberta Diabetes Institute IsletCore. Endocrinology 157(2):560-569. https://doi.org/10.1210/en.2015-1562
20. Chen Y-C, Colvin ES, Griffin KE, Maier BF, Fueger PT (2014) Mig6 haploinsufficiency protects mice against streptozotocininduced diabetes. Diabetologia 57(10):2066-2075. https://doi.org/ 10.1007/s00125-014-3311-z

21. Milgram SL, Kho ST, Martin GV, Mains RE, Eipper BA (1997) Localization of integral membrane peptidylglycine alpha-amidating monooxygenase in neuroendocrine cells. J Cell Sci 110:695-706

22. Courtade JA, Wang EY, Yen P et al (2017) Loss of prohormone convertase 2 promotes beta cell dysfunction in a rodent transplant model expressing human pro-islet amyloid polypeptide. Diabetologia 60(3):453-463. https://doi.org/10.1007/s00125-0164174-2

23. Gaier ED, Eipper BA, Mains RE (2014) Pam heterozygous mice reveal essential role for $\mathrm{Cu}$ in amygdalar behavioral and synaptic function. Ann N Y Acad Sci 1314:15-23. https://doi.org/10.1111/ nyas. 12378

24. Saunders DC, Brissova M, Phillips N et al (2019) Ectonucleoside triphosphate diphosphohydrolase-3 antibody targets adult human pancreatic $\beta$ cells for in vitro and in vivo analysis. Cell Metab 29(3):745-754. https://doi.org/10.1016/j.cmet.2018.10.007

25. Kim D, Langmead B, Salzberg SL (2015) HISAT: a fast spliced aligner with low memory requirements. Nat Methods 12(4):357360. https://doi.org/10.1038/nmeth.3317

26. Pertea M, Pertea GM, Antonescu CM, Chang T-C, Mendell JT, Salzberg SL (2015) StringTie enables improved reconstruction of a transcriptome from RNA-seq reads. Nat Biotechnol 33(3):290295. https://doi.org/10.1038/nbt.3122

27. Hu B, Jin J, Guo A-Y, Zhang H, Luo J, Gao G (2015) GSDS 2.0: an upgraded gene feature visualization server. Bioinformatics 31(8): 1296-1297. https://doi.org/10.1093/bioinformatics/btu817

28. Vishwanatha K, Bäck N, Mains RE, Eipper BA (2014) A histidinerich linker region in peptidylglycine $\alpha$-amidating monooxygenase has the properties of a pH sensor. J Biol Chem 289(18):12404 12420. https://doi.org/10.1074/jbc.M113.545947

29. Segerstolpe Å, Palasantza A, Eliasson P et al (2016) Single-cell transcriptome profiling of human pancreatic islets in health and type 2 diabetes. Cell Metab 24(4):593-607. https://doi.org/10.1016/j. cmet.2016.08.020

30. Bousquet-Moore D, Ma XM, Nillni EA et al (2009) Reversal of physiological deficits caused by diminished levels of peptidylglycine alpha-amidating monooxygenase by dietary copper. Endocrinology 150(4):1739-1747. https://doi.org/10. 1210/en.2008-1202

31. van der Heijden RA, Sheedfar F, Morrison MC et al (2015) High-fat diet induced obesity primes inflammation in adipose tissue prior to liver in C57BL/6j mice. Aging 7(4):256-268. https://doi.org/10. 18632/aging. 100738

32. Westwell-Roper C, Dai DL, Soukhatcheva G et al (2011) IL-1 blockade attenuates islet amyloid polypeptide-induced proinflammatory cytokine release and pancreatic islet graft dysfunction. $\mathrm{J}$ Immunol 187(5):2755-2765. https://doi.org/10.4049/jimmunol. 1002854

33. Yoo HJ, Kim M, Kim M, Chae JS, Lee S-H, Lee JH (2017) The peptidylglycine- $\alpha$-amidating monooxygenase $(P A M)$ gene rs13175330 $\mathrm{A}>\mathrm{G}$ polymorphism is associated with hypertension in a Korean population. Hum Genomics 11(1):29. https://doi.org/ 10.1186/s40246-017-0125-3

34. Obici S, Feng Z, Tan J, Liu L, Karkanias G, Rossetti L (2001) Central melanocortin receptors regulate insulin action. J Clin Invest 108(7):1079-1085. https://doi.org/10.1172/JCI12954

35. van den Hoek AM, van Heijningen C, Schröder-van der Elst JP et al (2008) Intracerebroventricular administration of neuropeptide $Y$ induces hepatic insulin resistance via sympathetic innervation. Diabetes 57(9):2304-2310. https://doi.org/10.2337/db07-1658 
36. Lo C-M, Obici S, Dong HH et al (2011) Impaired insulin secretion and enhanced insulin sensitivity in cholecystokinin-deficient mice. Diabetes 60(7):2000-2007. https://doi.org/10.2337/db10-0789

37. Long M, Zhou J, Li D, Zheng L, Xu Z, Zhou S (2015) Long-term over-expression of neuropeptide $\mathrm{Y}$ in hypothalamic paraventricular nucleus contributes to adipose tissue insulin resistance partly via the Y5 receptor. PLoS One 10(5):e0126714. https://doi.org/10.1371/ journal.pone. 0126714

38. Gayen JR, Saberi M, Schenk S et al (2009) A novel pathway of insulin sensitivity in chromogranin A null mice: a crucial role for pancreastatin in glucose homeostasis. J Biol Chem 284(42):28498 28509. https://doi.org/10.1074/jbc.M109.020636

39. Westermark P, Andersson A, Westermark GT (2011) Islet amyloid polypeptide, islet amyloid, and diabetes mellitus. Physiol Rev 91(3):795-826. https://doi.org/10.1152/physrev.00042.2009
40. Tu L-H, Serrano AL, Zanni MT, Raleigh DP (2014) Mutational analysis of preamyloid intermediates: the role of His-Tyr interactions in islet amyloid formation. Biophys J 106(7):1520-1527. https://doi.org/10.1016/j.bpj.2013.12.052

41. Abedini A, Plesner A, Cao P et al (2016) Time-resolved studies define the nature of toxic IAPP intermediates, providing insight for anti-amyloidosis therapeutics. eLife 5:e12977. https://doi.org/ 10.7554/eLife.12977

42. Shigihara N, Fukunaka A, Hara A et al (2014) Human IAPPinduced pancreatic $\beta$ cell toxicity and its regulation by autophagy. J Clin Invest 124(8):3634-3644. https://doi.org/10.1172/JCI69866

Publisher's note Springer Nature remains neutral with regard to jurisdictional claims in published maps and institutional affiliations. 